Aus dem I. Anatomischen Ingtítut der Wiener Universität. Vorgtand: Prof. Dr. Julute Tandler.

\title{
DIE ENTWICKLUNGSGESCHICHTE DES UROGENITALSYSTEMS BEIM MAULWURF (TALPA EUROPAEA)
}

VON

DR. FRANZ C. KRASA, ABSISTENT DES INSTITUTS.

Mit 20 Figuren im Text und 10 Figuren auf Tafel $37-41$. 
Eine Reihe von Fragen, welche die Phylogenese des Urogenitalsystems betreffen, kann einer Lösung erst dann zugeführt werden, wenn über die Ontogenese dieses Systems bei möglichst viel verschiedenen Arten vollkommene Klarheit herrscht. Trotzdem nun bis in die letzte Zeit zahlreiche Arbeiten erschienen sind, die zur Erreichung dieses Zieles sich auf 'die Erforschung, der Ontogenese einer einzigen Species beschränken, ist doch noch selbst in manchen ontogenitischen Fragen eine endgültige Einigung nicht erzielt worden. Mag das nun darauf beruhen, dass manchem Forscher keine lückenlose Kette von Embryonen zur Verfügung stand und er deshalb zu Hypothesen seine Zuflucht nehmen musste, oder einfach auf der Vielgestaltigkeit der äusseren Geschlechtsorgane, jedenfalls ist eine Klärung dieser Fragen noch ausständig. Einen Beitrag zu dieser Klärung soll die vorliegende Arbeit darstellen.

Für die Wahl des' Untersuchungsobjektes war einerseits die Utberlegung massgebend, dass der verhältnismässig einfache Bau der Genitalorgane von Talpa europaea die Untersuchung erleichtern werde, andererseits die, Möglichkeit aus der grossen Zahl der Talpaembryonen des I. anatomischen Institutes der Wiener Universität eine ununterbrochene Reihe von Entwickelungsstadien auswählen zu können.

Die Embryonen wurden in einer der gebräuchlichen Lösungen konserviert, in Paraffin eingebettet und in fortlaufende Schnittserien von $10 \mu$ Dicke zerlegt. Die Färbung geschah mit Hämalaun-Eosin. 
Die in den Figuren dargestellten Modelle wurden nach dem $\mathrm{B}$ o r $\mathrm{n}$ schen Plattenmodellierverfahren gewonnen, die Konturzeichnungen mit Hilfe des' Z eiss-A b.beschen Zeichenapparates angefertigt.

Die vorliegende Arbeit gliedert sich in fünf Kapitel, von denen das erste die Beschreibung der Entwickelungsstadien enthält.

Die vier folgenden bilden zine Zusammenfassung des ganzen Themas und einen Vergleich meiner Befunde mit den Ergebnissen früherer Arbeiten; und zwar behandelt das zweite Kapitel die Teilung der Cloake und die Bildung des Dammes, das dritte die Umwandlung des Urogenitalhöckers in die äusseren Geschlechtsteile, das vierte Kapitel die Formveränderungen der Analregion. Das fünfte Kapitel bespricht in kurzen Zügen die Ausbildung der inneren Harn- und Geschlechtsorgane:

Für die Ubertragung der Arbeit und die vielfache Unterstützung bei der Ausführung spreche ich auch an dieser Stelle meinem verehrten Chef und Lehrer Herrn Prof. Dr. Julius Tandler meinen ergebensten Dank aus.

\section{Beschreibung der Entwicklungsstadien.}

\section{Stadium (Serie 21).}

Das Stadium, bei dem der Grundstock der späteren Cloake das erstemal nachweisbar ist, ist in seinem Entwickelungszustand durch folgende Beschreibung charakterisiert:

Der Embryo ist spiralig eingedreht; es kann daher von einer Angałe des Längenmasses um so eher abgesehen werden, als ja auch bei gestreckten Embryonen, die leichter gemessen werden können, die gewonnenen Masse nicht immer mit dem Ausbildungsgrad des Embryo übereinstimmen.

Die primären Augenblasen sind von dem noch nicht verdickten Ectoderm durch eine sehr feine Schicht Mesoderm ge: 
trennt. Die Hörblässchen sind eben abgeschnürt und mit dem Ectoderm nicht mehr im Zusammenhang. Die Decke des vierten Ventrikels ist stark verdünnt. Zwei Kiemenfurchen und zwei Kiemenbögen sind angelegt. Das Herz ist im Schleifenstadium; die Trabekelbildung beginnt.
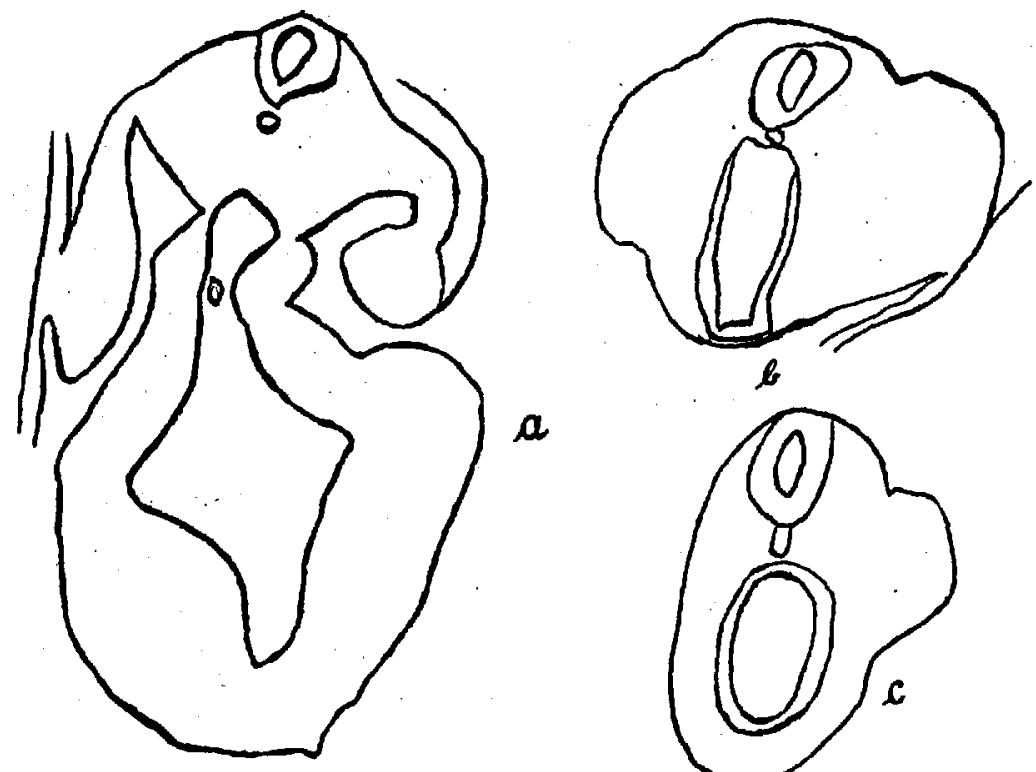

Figur 1.

3 Schnitte durch das untere Körperende eines Embryo von 2,5 mm Scheitel-Steisslänge. $1 \times 75$.

Der Darm zieht von der hinteren Darmpforte als ziemlich schmales Rohr weiter und verbreitert sich plötzlich zu einem. mächtigen Hohlraum, der beinahe den ganzen Hinterleib des Embryo ausfüllt. Am Transversalschnitt reicht er von der Chorda dorsalis bis an die ventrale Bauchwand heran (Schnittb, Textfigur 1). Der Querschnitt dieses Raumes ist längsoval und bei weitem größer als der des Neuralrohres. Seine Wandung wird von einer Schicht hoher Entodermzellen gebildet. Die 
ventrale Wand dieser Darmiendkammer stülpt sich in ihrem oralen Anteil als eine grosse Blase aus, deren Wand von einer Reihe ganz niederer Epithelzellen gebildet und von einer dicken, zahlreiche Gefässe enthaltenden Schicht Mesoderm umgeben ist (Schnitt a). Diese Blase, die Allantois, ist jetzt noch ohne deutlichen Stiel in ihrer ganzen Breite mit der Darmendkammer in Verbindung. Äusserlich setzt sie sich durch eine Furche von den übrigen Anteilen ab.

Knapp caudal von der Allantois sieht man die ventrale Wand der Darmendkammer mit dem Ectoderm in Berührung treten und mit ihm verschmelzen. Diese. Verbindung ist auf fünfen der zehn Mikren dicken Schnitte deutlich zu sehen (Schnitt b). Die in caudaler Richtung folgenden Schnitte zeigen in unmittelbarer Fortsetzung dieser Ecto-Entodermverbindung eine Zellmasse, in der die verschiedenen Keimblätter ineinander überzugehen scheinen. Wir haben es hier mit Anteilen des Primitivstreifens zu tun. Der Grenzschnitt zwischen diesem und der Ecto-Entodermverbindung zeigt ein ähnliches Bild, wie das von Andersson als Figur $2 \mathrm{~b}$ gebrachte; in der Medianlinie haben sich das äussere und das innere Keimblatt bereits vereinigt, während lateral davon noch einzelne Zusammenhänge dieser Vereinigung mit dem mittleren Keimblatt zu sehen sind. Dieses und :ahnliche Bilder, die sich bei der Durchsicht anderer Serien desselben Stadiums auffinden lassen, sprechen dafür, dass in den cranialen Partien des Primitivstreifens beginnend das Mesoderm die Verbindung mit den anderen Keimblättern verliert und dadurch die Vereinigung des inneren und äusseren Keimblattes ermöglicht.

Ebenso plötzlich, wie der Darm sich zur Endkammer erweitert, ist diese am' caudalen Ende abgeschlossen.

\section{Stadium' (Serie 6, Tafelfigur 1).}

Der spiralig eingedrehte Embryo zeigt die vorderen Extremitäten angelegt, die hinteren angedeutet. Die primären 
Die Entwickelungsgeschichte des Urogenitalsystems beim Maulwurf. 449

Augenblasen sind in weiter Kommunikation mit dem Prosencephalon. Sie reichen bis an das Ectoderm heran, das an dieser Stelle deutlich verdickt ist. Die Hörbläschen sind, mit jenen des früher beschriebenen Stadiums verglichen, bedeutend grösser. Ihre mediale vordere Wand zeigt entsprechend der Anlagerung des Nervus acusticus eine deutliche Verdickung des Epithels. Der Ductus endolymphaticus beginnt sich zu entwickeln. Drei Kiementaschen erreichen das Ectoderm, eine vierte ist angelegt. Die mediane Thyreoideaanlage ist an einer Stelle mit dem Pharynxepithel in Zusammenhang. Die Trachea ist zweigeteilt. Einige Lebertrabekel sind angelegt.

Durch die Einmündung der Urnierengänge ist aus der beim vorigen Stadium 'beschriebenen Darmendkammer die Cloake geworden.: Dieșe stellt einen grossen spaltförmigen Hohlraum mit rechteckigem Aufriss vor. An dem 200 fach vergrösserten Modell gemessen beträgt die Höhe dieses Raumes ca. $75 \mathrm{~mm}$, der sagitlale Durchmesser $40 \mathrm{~mm}$, während die Breite zwischen 6 und $10 \mathrm{~mm}$ schwankt.

Am caudalen vorderen Winkel geht ein Divertikel des Hohlraumes in beinahe rechtem Winkel von der Cloake ab. Er ist, eng der Chorda angelagert, als Schwanzdarm noch ein Stück weit in den sich nunmehr deutlich gegen den Körper absetzenden Schwanz hinein zu verfolgen. Sein Durchschnitt ist kreisförmig und dem Neuralnohr an Grösse gleich, übertrifft also den des Enddarmes (Schnitt d, Textfigur 2).

Ventral und cranial geht von der Cloake der Allantoisstiel ab. Er ist ein dünnwandiges Rohr mit sehr weitem Lumen (Schnitt a, b).

Die Ductus Wolffi haben beiderseits die Cloake erreicht und münden mit leicht angedeuteten trichterförmigen Erweiterungen in unmittelbarer Nähe der als Cloakenmembran zu bezeichnenden Verschmelzung zwischen Ecto- und Entoderm in die Cloake (Schnitt $a-c)$. 

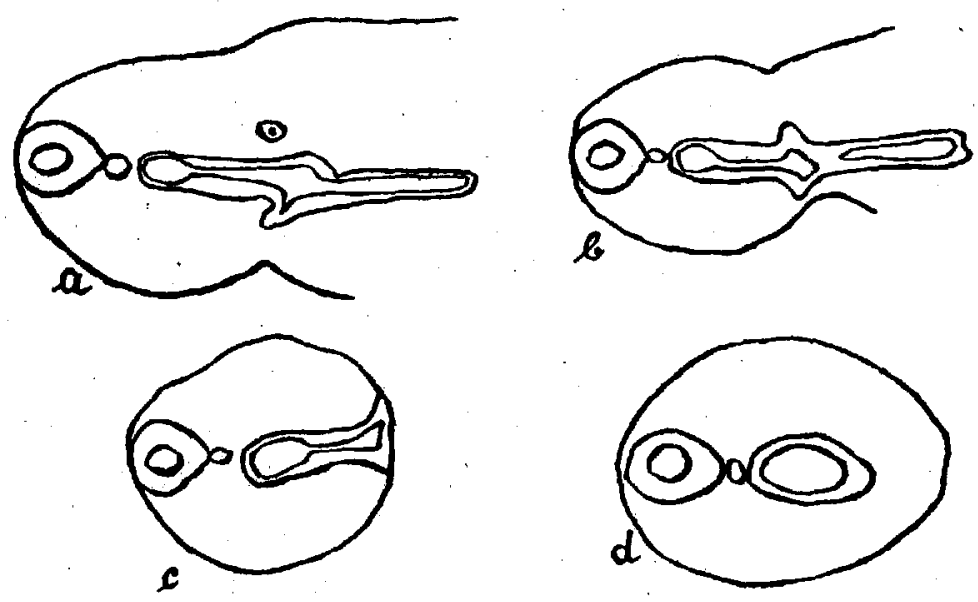

Figur 2.

4 Schnitte durch das untere Korperende eines Embryo von $3,5 \mathrm{~mm}$ gr. 1 . $1 \times 75$.

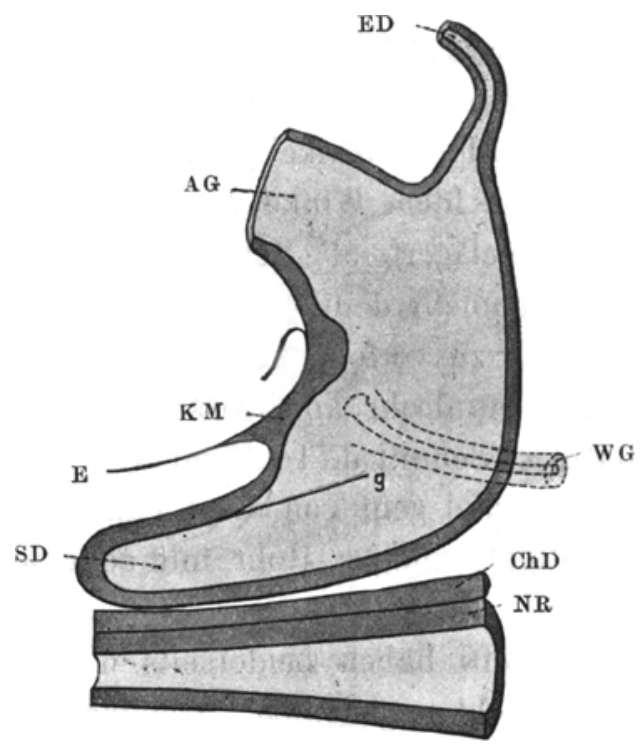

Figur 3.

Sagittalrekon struktion der Kloake eines Embryo von $3,5 \mathrm{~mm}$ gr. L. Vergrosserang $1 \times 100$. g Grenze zwischen dem hohen (Kloaken-) and niedern (Darm-) Epithel. 
Die Entwickelungsgeschichte des Urogenitalsystems beim Maulwurf. 451

Die Stelle der Cloakenmembran ist am Modell äusserlich nicht zu erkennen, da die Membran im Niveau des Integumentes gelegen ist. Sie liegt knapp caudal vom Allantoisstiel, dort wo man am Modell, das in Figur 1 auf Tafel 00 dargestellt ist, die Cloakenwand mit dem Ectoderm zusammenstossen sieht. Die Untersuchung der Serie zeigt die beiden Keimblätter im Bereiche der Cloakenmembran vollkommen miteinander verschmolzen.

Das Epithel des Darmrohres setzt sich unverändert auf die Cloake fort. Es erreicht aber in den Partien um die Mündungen der Urnierengänge eine grössere Höhe, so dass diese Teile gegen das niedere Allantoisepithel scharf abstechen. Besonders deutlich markiert ist die Grenze aber gegen das gleichfalls niedere Epithel des Schwanzdarmes. Es entstehen durch den plötzlichen Utbergang des Epithels zwei an der lateralen Cloakenwand in der Richtung und als Fortsetzung der vorderen Wand ides Schwanzdarms verlaufende Falten, so dass sich dieser, der äusserlich kaum durch eine seichte Furche von der Cloake getrennt ist, an der Innenwand sehr deutlich gegen den Cloakenhohlraum begrenzt. An der Sagittalrekonstruktion, die bei 200 facher Vergrösserung angefertigt wurde, ist diese Grenze durch die Linie g gekennzeichnet (Textfigur 3).

Im Epithel der Cloakenmembran und der ihr benachbarten Mündungen der Urnierengänge sieht man zahlreiche Mitosen, in dem um diese Anteile gelegenen Mesoderm deutliche Verdichtungszonen, als Ausdruck der lebhaften Wachstumtendenz, die diesen Teilen in der Weiterentwickelung der Cloake die führende Rolle verschafft, während die dorsale Cloake, in der man nur wenig Kernteilungsfiguren sieht, von nun an nur einem langsamen stetigen Wachstum unterliegt, ohne aber dadurch in ihrer Gestalt stärker beeinflusst zu werden. 
III. Stad i u m (Serie 7, Tafelfigur 2).

Der Embryo ist $5 \mathrm{~mm}$ lang. Er besitzt eine sekundäre Augenblase und ein weit offenes Linsengrübchen. Der Ductus
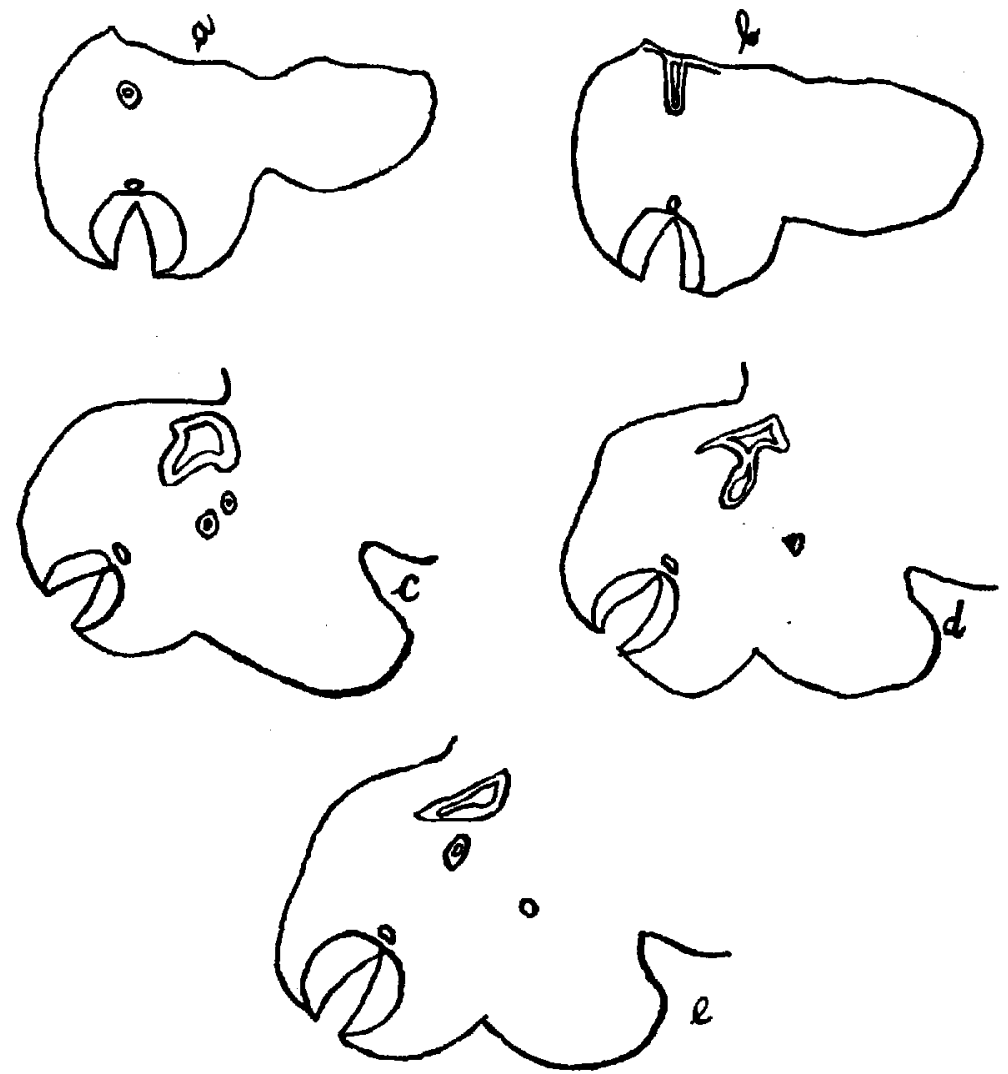

Figur 4.

5 Schnitte durch das untere Korperende eines Embryo von $5 \mathrm{~mm}$ gr. L. $1 \times 40$.

endolymphaticus beginnt sich abzugrenzen. Im Riechgräbchen ist das J a cobs ohn sche Organ durch eine leichte Einziehung der medialen Epithelbekleidung angedeutet. Ein fünfter Aortenbogen ist ausgebildet. Im Vorhof ist das Septum primum deutlich entwickelt. 
Die Entwickelungsgeschichte des Urogenitalsystems beim Maulwurf. 453

Während die dorsale Wand der Cloake im zweiten Stadium überall in nächster Nähe der Chorda dorsalis gelegen war, hat sie sich jetzt um ein bedeutendes Stück von ihr entfernt. Auch der Schwanzdarm liegt, soweit er der Spiraldrehung des Schwanzes wegen verfolgbar ist, der ventralen Leibeswand viel näher als der Chorda (Schnitt a, Textfigur 4). Der sagittale Durchmesser der Cloake hat sich gegen das frühere Stadium

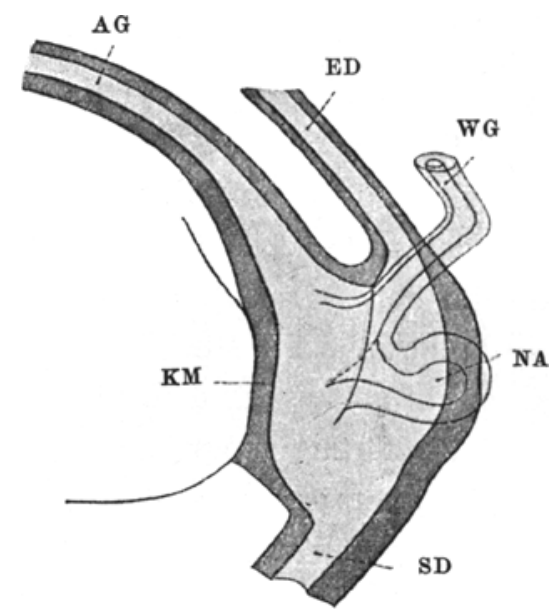

Figur 5.

Sagittalrekonstruktion der Cloake eines Embryo von $5 \mathrm{~mm}$ gr. L. Vergrosserung $1 \times 100$.

nicht sehr geändert. Ihre Höhe hingegen hat bedeutend abgenommen, wovon man sich durch einen Vergleich der beiden Sagittalrekonstruktionen dieses (Textfigur 5) und des vorhergehenden Stadiums, welche bei derselben Vergrösserung angefertigt wurden, leicht überzeugen kann. Die zu vergleichenden Höhenmasse sind der Abstand zwischen der ventralen Grenze des Schwanzdarmes und dem tiefsten Punkt der oralen Cloakenwand zwischen Allantois und Enddarm.

Diese Höhenabnahme ist auf eine Veränderung der oralen Cloakenwand zurückzuführen. Man sieht nämlich, dass der 
Allantoisstiel, der in früheren Stadien beinahe rechtwinklig aus der Cloake abgebogen ist, jetzt in einem' nach ventral schwach konkaven Bogen aus der oralen Cloakenwand aufsteigt. Er wird durch eine Schicht Mesoderm, die zwischen ihm und dem Darm die orale Cloakenwand einstülpt, von dem Darm getrennt. Diese Vorwölbung, die als Darmsattel beschrieben wird, reicht nicht ganz bis zur Höhe der Einmündungsstelle der Urnierengänge und bis zum cranialen Ende der Cloakenmembran herab. Schon in diesem Stadium hat der Darmsattel seine charakteristische Gestalt, indem nämlich sein unterer Rand vom Cloakenhohlraum aus gesehen als halbmondförmig. in idas Lumen vorspringende Falte imponiert und indem er das Lumen der Cloake derart teilt, dass auf Transversalschnitten durch die Cloake, die den Darmsattel treffen, das dorsale am Schnitt (Schnitt e) kreisrunde Teilstück, der Darmabschnitt der Cloake, von dem ventral gelegenen, dem Sinus urogenitalis und der Blasenanlage, bogenförmig umgriffen wird. Dies tritt dadurch noch deutlicher hervor, dass der ventrale Anteil der Cloake auf Grundlage der früher erwähnten Trichtermündungen der Urnierengänge zwei seitlich und nach hinten gerichtete Divertikel ausbildet, die Cloakenhörner (Schnitt c, d, e). Diese Cloakenhörner haben die ganzen Seitenwände desl ventralen Cloakenteiles in sich einbezogen, so dass sie sich sogar bis zum Abgang des Allantoisstieles hin erstrecken und auch auf die noch ungeteilte Cloake hinabreichen. Damit hängt esı zusammen, dass der Querschnitt der Cloake unterhalb des Darm. sattels T-Form aufweist.

Der vertikale Balken des' $\mathrm{T}$ wird von dem unverändert schmal gebliebenen dorsalen Teil der Cloake, der horizontale von dem durch Ausbildung der Hörner transversal erweiterten ventralen Teil gebildet. Der rechte Winkel, der gerade an der Berührungsstelle der beiden Anteile zu sehen ist, entsteht dadurch, dass hier die hintere Begrenzung des Cloakenhornes 
Die Entwickelungsgeschichte des Urogenitalsystems beim Maulwurf. 455

mit ider kleinen Falte, die den Ausläufer des Darmsattels bildet, zur Vereinigung kommt. Dieser Winkel scheidet gleichzeitig das hohe, mit mehreren Kernreihen ausgestattete Epithel des ventralen Abschnittes von dem niederen einreihigen, das den dorsialen Anteil der Cloake bildet.

An der Kuppe der Cloakenhörner münden die Urnierengänge, die kurz vor ihrer Einmündung an ihrer dorsalen Wand eine kurzgestielte, beiläufig kugelförmige Ausstülpung tragen, die im messonephrogenen Gewebe eingebettet liegt. Es handelt sich um die Anlage des Ureters und des Nierenbieckens.

Die dorsal und caudal liegenden Teile der Cloake haben sich in Gestalt und Grösse nur wenig verändert. Der Schwanzdarm hingegen ist bedeutend dünner und länger geworden. Auch hat er seine Lage geändert, indem er nicht mehr rechtwinklig von der Cloake abgeht. Seine Achse bildet jetzt die direkte Fortsetzung des Bogens, der vom Enddarm und der dorsalen Cloakenpartie gebildet wird. Auch ist die im früheren Stadium in der Textfigur 3 als Linie g gekennzeichnete Falte verschwunden. Die Lageänderung des Schwanzdarmes ist wohl hauptsächlich auf eine beginnende Streckung des Embryo zurückzuführen, die bereits' beimi nächsten Staidium deutlicher wird. An der Abgangsstelle des Schwanzdarmes sieht man am Modell eine leichte Einziehung. Der Schwanzdarm selb'st wurde am Modell abgeschnitten.

Was schliesslich noch die Cloakenplatte betrifft, so sieht man, dass sie in caudaler Richtung in die Länge gewachsen ist. Sonst hat sich weder in ihrer Lage noch in ihrer Zusammensetzung irgend etwas geändert.

IV. Stadium (Serie 38, Tafelfigur 3).

Der Embryo hat eine grösste Länge von $6 \mathrm{~mm}$, die Kopflänge beträgt $4 \mathrm{~mm}$. Die Retina enthält bereitss Pigment. Die laterale Bogentasche ist zu erkennen, die vordere und hintere 
Bogentasche sind gemeinsam angelegt, der Ductus cochlearis zeigt eine leichte Krümmung. Der Riechschlauch trägt deutlich die Anlage des Jacobsohnschen Organs als eine mediale Rinne. Die Membrana bucconasalis ist bereits gebildet. Der dorsale Rest des zweiten Aortenbogens beginnt sich zur Anlage der Arteria stapedia zu verlängern. Die Bulbuswülste 1 und 3 sowie A und B berühren sich. Das Foramen interventriculare ist offen. Die Nabelhernie besteht aus einer einzigen Darmschlinge.

Die am meisten auffallende Veränderung dieses Stadiums gegen die früheren ist durch das Auftreten eines niederen Wulstes bedingt, der in transversaler Richtung verlaufend, den ganzen Raum zwischen Bauchstiel und dem bereits mehr vom Körper abgestreckten Schwanz ausfüllt. Lateralwärts geht er ohne deutliche Grenze in die Rumpfwand über, während oral und caudal seine Grenzen durch scharfe Furchen gekennzeichnet sind. Man bemerkt leicht, dass dieser Wulst nicht gleichmässig gewölbt ist, sondern dass die Wölbung nur den oralen Teil betrifft, während der caudale Anteil flach ist und steil gegen die Schwanzwurzel absteigt.

Die Cloake hat eine Formveränderung begonnen, die offenbar mit der Ausbildung dieses Wulstes zusammenhängt, um so mehr als die Cloakenmembran mit dem Ectoderm des Wulstes vorgestülpt wurde. Sie liegt jetzt am caudalen Abfall des Wulstes in der Medianebene und reicht von der caudalen Grenzfurche bis zu seiner höchsten Erhebung. Die anschliessenden Cloakenteile wurden von dieser Umlagerung mitbetroffen. Die caudale Partie des Wulstes ist durch einen Zellgrat (Schnitt e, Textfigur 6), der von der oralen Wand des Cloakenhohlraumes bis zur Membran zieht und mit dieser in ihrer ganzen Ausdehnung in Verbindung steht, median geteilt. Diese solide Zellmasse ist mit der Cloakenmembran so verschmolzen, dass sie zusammen ein untrennbares Ganzes darstellen, und dass man 
für dieses neue Gebilde auch einen eigenen Namen anführen muss. Von den zahlreichen Namen, die für diese Bildung gebraucht werden, glaube ich den Ausdruck Cloakenplatte als den präzisesten annehmen zu können. Ubber die Art der Ent-
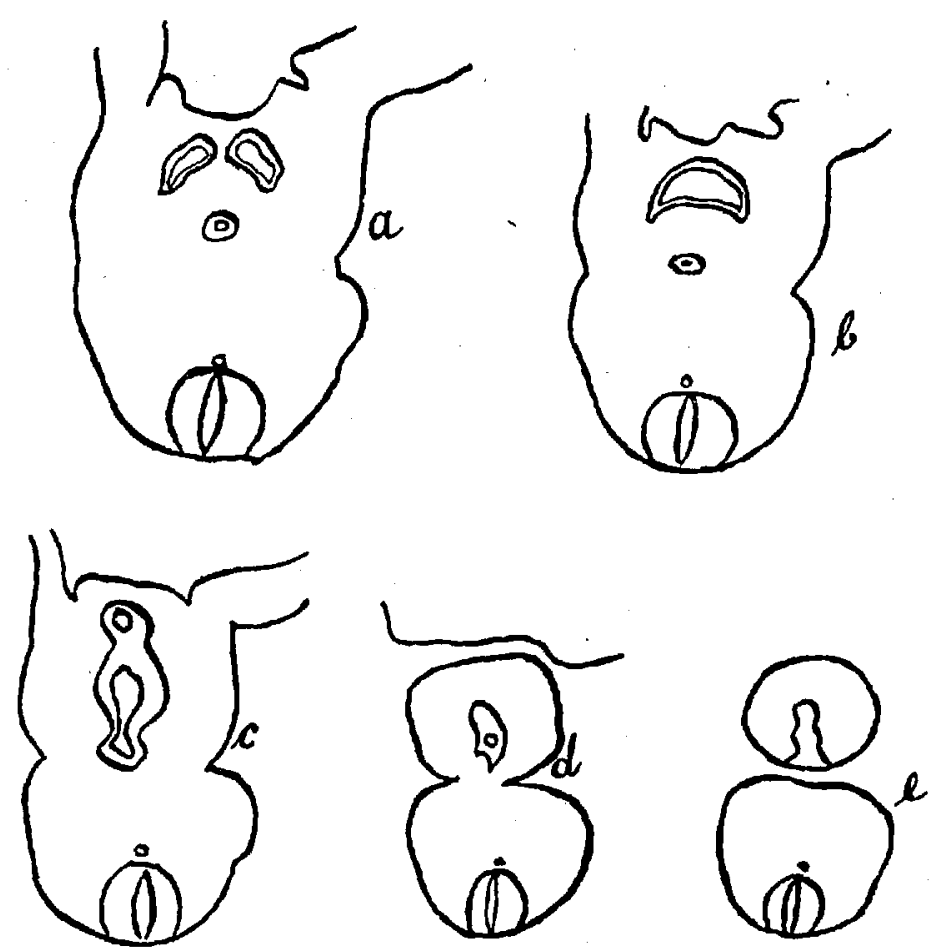

Figur 6.

5 Schnitte durch das untere Körperende eines Embryo von $6 \mathrm{~mm} .1 \times 40$.

stehung dieser Cloakenplatte werde ich an geeigneter Stelle sprechen.

Auch die ventralen und oralen Partien der Cloake habien bedeutende Umgestaltungen erfahren. Der Sinus urogenitalis hat sich stark vergrössert, besonders sind aber die Cloakenhörner gewachsen (Schnitt a). Sie erstrecken sich viel weiter 
cranialwärts als im früheren Stadium. An ihrer Kuppe münden Wolffscher Gang und Ureter nebeneinander.

Durch diese Verschiebung des Sinus urogenitalis in cranialer Richtung einerseits, andererseits aber durch ein caudalwärts gerichtetes Wachstum des Darmsaltels ist die Teilung der Cloake in diesem Stadium wieder weiter fortgeschritten. Dass der Darmsattel wirklich in die Cloake hineingewachsen

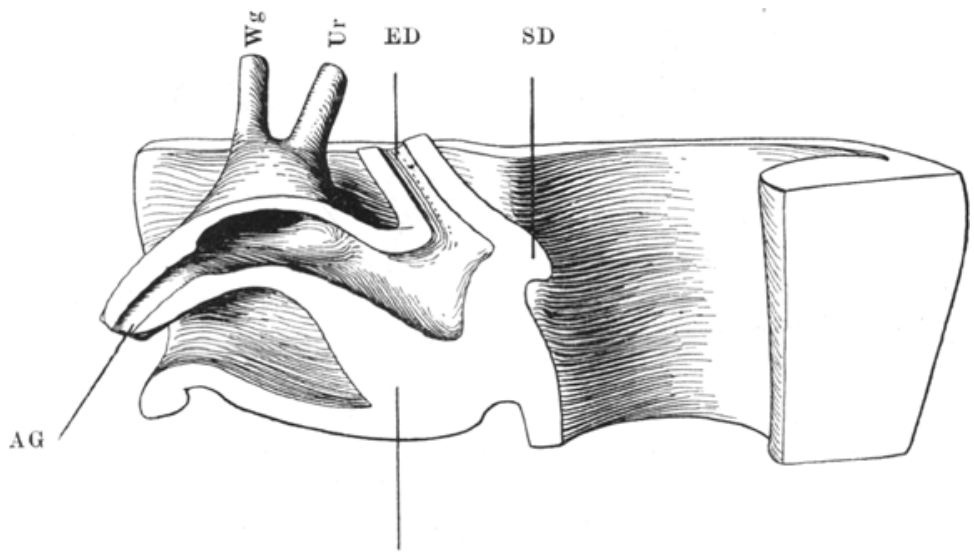

KP

Figur 7.

Sagittalschnitt durch das Modell eines Embryo von $6 \mathrm{~mm}$ gr. L. Modellvergrösserung $1 \times 200 ; 1 / 2$ Modellgrösse.

ist, kann wie beim vorigen Stadium durch ein genaues $\mathrm{Ab}$ messen des Abstandes zwischen dem tiefsten Punkt des Darmsattels und dem Abgang des Schwanzdarmes bewiesen werden.

Dieser Vergleich ist am besten möglich an dem Sagittalschnitt dieses Modells (Textfigur 7) und den abgebildeten Sagittalrekonstruktionen der früheren Stadien.

Die Abgangstelle des Schwanzdarmes ist am caudodorsalen Winkel der Cloake als ein kurzer Epithelspross zu sehen. Reste des Schwanzdarmes sind in dem Mesoderm des Schwanzes eingelagert nachzuweisen. 
Die Entwickelungsgeschichte des Urogenitalsystems beim Maulwurf. 469

Infolge des Weiterfortschreitens der Cloakenteilung sind die formalen Eigentümlichkeiten des Darmsattels, des Sinus urogenitalis und der Cloake viel ausgeprägter als bei dem vorher beschriebenen Stadium, und aus den beigegebenen Schnittbildern leicht zu entnehmen. Auch zeigen diese Schnittbilder besser als der Sagittalschnitt des Modells, wie weit die Cloake in diesem Stadium schon in den Höcker verlagert ist.

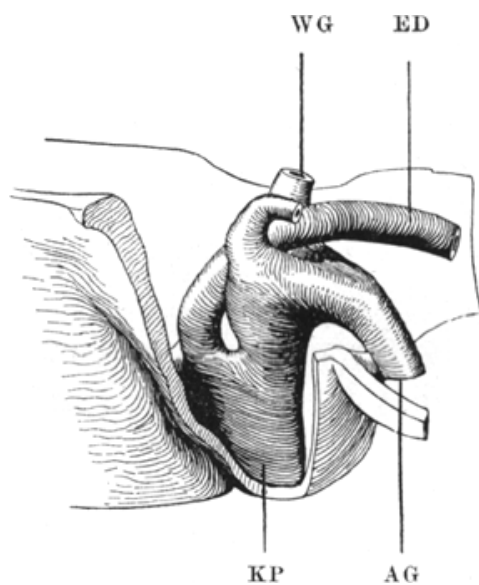

Figur 8.

Modell des Sinus urogenitalis und des Anourogenitalhöckers eines Embryo von $8 \mathrm{~mm}$ Scheitel-Steisslange, von rechts gesehen. Das Ektoderm des Höckers teilweise entfernt. Modellvergr. $1 \times 100 ; 1 / 2$ der Modellgrösse.

\section{Stadium (Serie 12).}

Der Embryo hat eine Scheitelsteisslänge von $8 \mathrm{~mm}$. In der Retina ist reichlich Pigment entwickelt, die vordere und die hintere Bogentasche sind winklig gegeneinander abgeknickt; der laterale Bogengang ist bereits in Abschnürung begriffen. Die Schnecke zęigt eine halbbogenförmige Krümmung. Das sekundäre Foramen ovale und das Foramen interventriculare sind weit offen.

Der früher beschriebene Wulst hat in seiner Ausbildung bedeutende Fortschritte gemacht (Textfigur 8). Er hat sich zu 
einem deutlich ausgeprägten Höcker differenziert, der mit seinem breitesten Anteil, der Basis, der ventralen Körperfläche des Embryo zwischen Bauchstiel und Schwanzwurzel aufsitzt und den Raum zwischen diesen Gebilden vollständig ausfüllt, so dass sich seine orale Seite an die caudale Wand des Nabelstranges, besonders innig aber sein caudaler Abfall an die ventrale Wand des Schwanzes anlegt. Seitlich ist der Höcker durch eine seichte Furche gegen das übrige Ectoderm abgegrenzt. Dieser Höcker stellt als Anourogenitalhöcker die Anlage der äusseren Genitalorgane, des Dammes und des Afters vor. Am Modell wurde rechts das Ectoderm des Höckers entfernt und man sieht durch diese Lücke die Cloakenplatte. Sie hat mit dem Wachstum des Höckers Schritt gehalten und nimmt, genau wie in dem früheren Stadium, die mediale Partie der caudalen Höckerhälfte für sich in Anspruch. Sie erstreckt sich noch immer vom Grund des Höckers bis zu seiner Spitze. Der noch nicht aufgeteilte Rest der Cloake ist ganz in den Höcker hineingerückt.

Die Teilung der Cloake ist weiter fortgeschritten. Der Enddarm steht nur mehr durch ein kurzes Rohr, von $\mathrm{Fle}$ is $\mathrm{ch}$ man $\mathrm{n}$ als Analrohr bezeichnet, mit dem Sinus urogenitalis in Verbindung. Dieser hat an Höhe zugenommen und erscheint in sagittaler Richtung flachgedrückt. Die Cloakenhörner, die gleichfalls schmäler und höher geworden sind, biegen dorsalwärts um, so dass der Sinus urogenitalis am Querschnitt noch die Gestalt einer Sichel aufweist. Sein Lumen folgt, da die Wände nirgends eine Verdickung aufweisen, ziemlich genau seiner Form und reicht bis in den Anourogenitalhöcker hinein.

Diesem Stadium gehört auch der in Figur 9 dargestellte Sagittalschnitt an. Es handelt sich um den medianen Schnitt der sagittal geschnittenen Serie $S_{2}$ (Serie 16). Der Embryo hat eine Länge von $8 \mathrm{~mm}$. Man sieht das am Sagittalschnitt schmale Lumen des Sinus urogenitalis durch das kurze Analrohr in 
Die Entwickelungsgeschichte des trogenitalsystems beim Maulwurf. 461

offener Verbindung mit dem Enddarm. Das Analrohr ist durch eine schmale Schicht Epithel von der Oberfläche des caudalen Höckerabfalls getrennt.

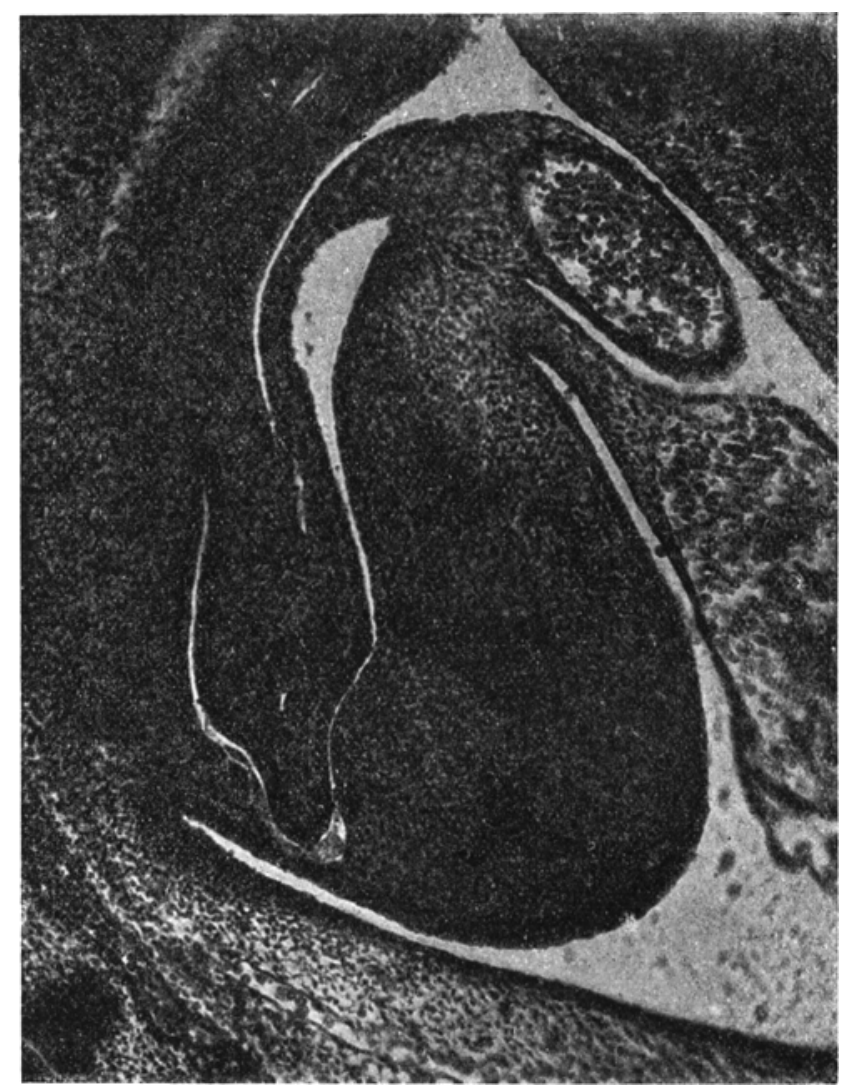

Figur 9.

Mediansagittalschnitt der Serie $S_{2}$.

Eine Zwischenstufe $z$ wischen diesem und dem folgenden Stadium bildet der Embryo $\mathrm{S}_{3}$ (Serie 17), der 8,5 mm lang ist. Der in Figur 10 dargestellte Mediansagittalschnitt zeigt den Mesodermsattel wieder caudalwärts vorgewachsen. Er hat den letzten Rest der Cloake unterteilt und dringt in die Cloaken- 
platte vor. Diese selbst unterliegt an dieser Stelle einem Rückbildungsvorgang; man sieht rings um den vordringenden Mesodermsporn eine hellere Zone als Ausdruck der Degenerations-

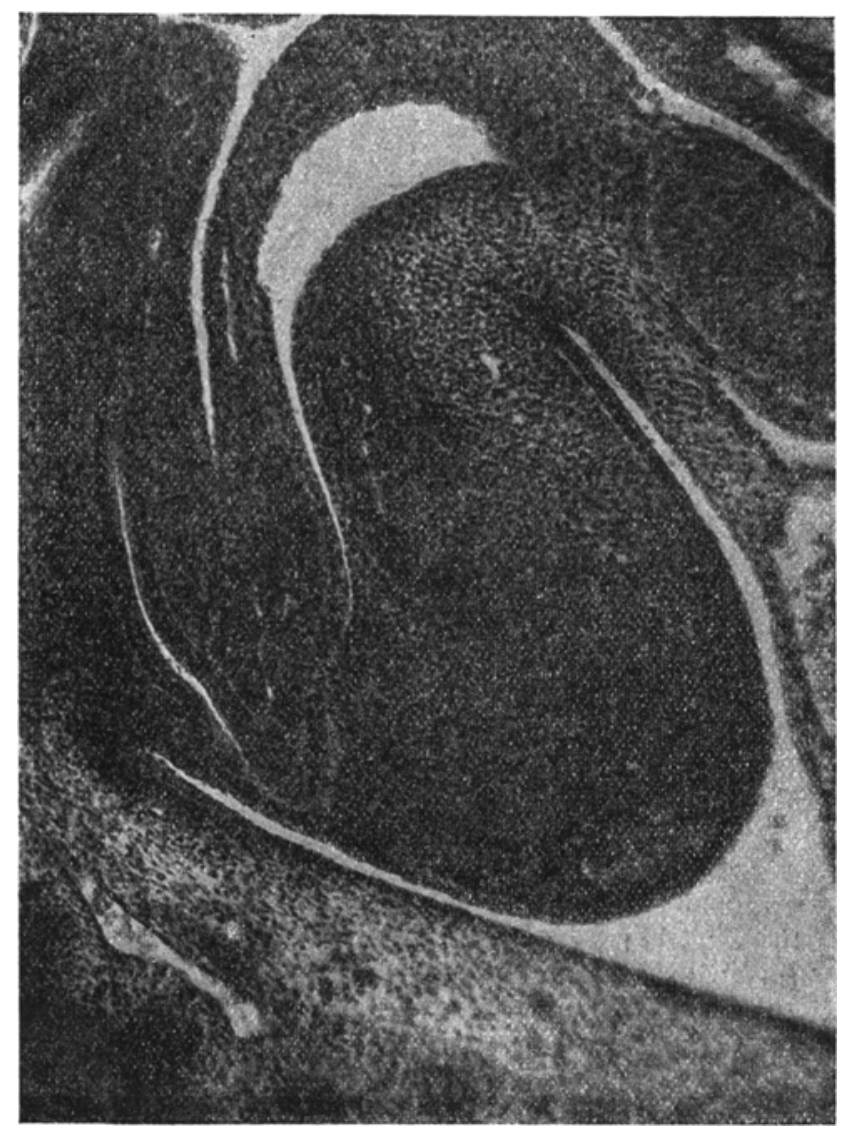

Figur 10.

Mediansagittalschnitt der Serie $S_{3}$.

vorgänge der Zellen. Der Sinus urogenitalis hat in dem der Cloakenplatte anliegenden Teil sein Lumen eingebüsst. Seine oralen Teile beginnen sich $z \mathrm{u}$ erweitern, der Anourogenitalhöcker ist wieder gewachsen. 
Die Entwickelungsgeschichte des trogenitalsystems beim Maulwurf. 463

VI. St a di u m (Serie 41, Tafelfigur 4).

Die Scheitelsteisslänge dieses Embryo beträgt $11 \mathrm{~mm}$. Die Gaumenleisten sind neben der Zunge vertikal eingestellt. An der Zahnleiste sieht man die Zahnanlagen im knospenförmigen Stadium. Die äusseren Nasenöffnungen sind durch Epithelwucherungen fast vollständig verschlossen.

Die linke Lunge ist nur im Bereiche des Unterlappens entwickelt, der Lobus' cardiacus gut ausgebildet. Der Embryo besitzt eine grosse Nabelhernie. Das Herz ist vollkommen unterteilt, in den grossen Arterien werden die Anlagen der Semilunarklappen bereits dünner.

An diesem Modell sieht man zum erstenmal die Teilung der Cloake in Sinus urogenitalis und Enddarm vollzogen. Dementsprechend ist nun auch die präcaudale Bauchwand nicht mehr durch den einheitlichen Anourogenitalhöcker eingenommen, sondern man sieht, dass die ganze Region in zwei Teile geteilt ist, in die Analregion und den Urogenitalhöcker. Ebenso ist die Cloakenplatte in zwei, diesen Regionen entsprechende Abschnitte unterteilt.

Der Urogenitalhöcker ragt als ein. freier Zapfen in oraler Richtung aus der Bauchwand auf. Er ist um vieles höher und schmäler geworden. Seine Basis wird von zwei plumpen Wülsten flankiert, die, sich stark verschmälernd, auf der oralen Seite der Höckerwurzel ineinander überzugehen scheinen. Die Cloakenplatte hat ihre Lage nicht geändert, sie ist aber relativ niedriger geworden (Schnitt a-c, Textfigur 11). Der Sinusl urogenitalis bildet jetzt einen in sagittaler Richtung zusammengepressten Schlauch. Die seitlichen Divertikel, in die der Urnierengang und der Ureter mündeten, sind geschwunden. Die Ureteren münden an einer nur wenig verbreiterten Stelle der Blasenanlage, einige Schnitte oral von der Mündung der W o l f f schen Gänge (Schnitt c). Diese münden an der Dorsalwand des 
464

FRANZ C. KRASA,
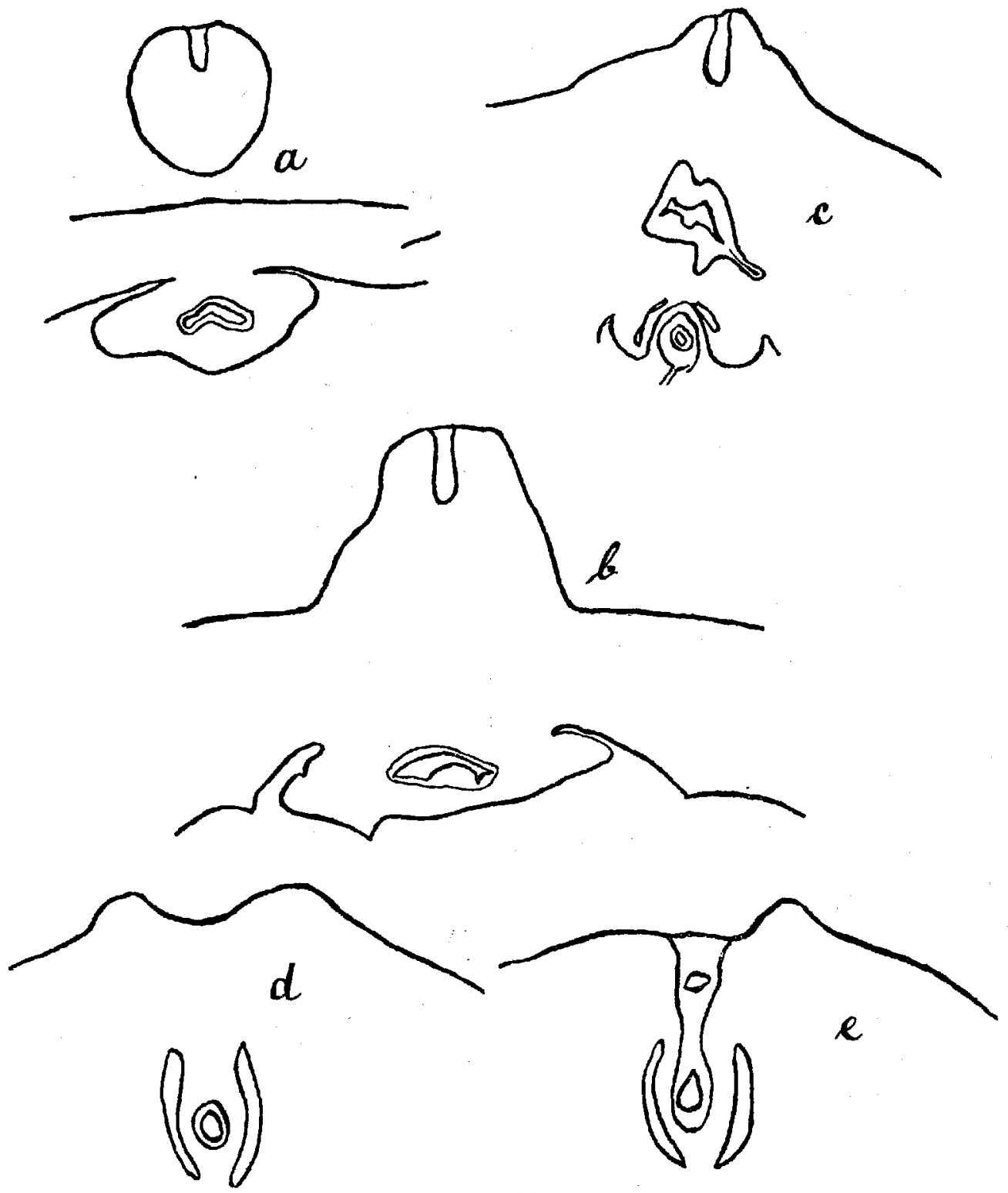

Figur 11.

5 Schnitte durch das untere Körperende eines Embryo von $11 \mathrm{~mm}$ Scheitel-Steisslänge. $1 \times 40$. 
Die Entwickelungsgeschichte des Urogenitalsystems beim Maulwurf. 465

Sinus, ziemlich nahe beieinander, an einer Stelle, die im Innern durch eine kugelförmige Erhebung des Epithels gekennzeichnet ist.

Die Analregion ist cranial durch den Höcker, caudal durch den stark ventral gekrümmten Schwanz begrenzt. Die laterale Begrenzung wird durch zwei distinkt abgegrenzte Höckerchen beigestellt, so dass die Gegend eingesunken erscheint und eine Grube bildet. In ihrer Tiefe liegt der caudale Teil der Cloakenplatte, der durch den vorwachsenden Darmsattel abgetrennt wurde und jetzt als Analplatte den Verschluss des Darmes bildet (Schnitt e). Die Analplatte ist in diesem Stadium bereits im Beginne der Degeneration, wie ausı der Serie ersichtlich ist.

Der zwischen Höcker und Analplatte liegende Teil der Analregion ist der Damm (Schnitt d). Er ist durch eine Epithelverdickung, die das' anale Ende der Cloakenplatte mit der Analplatte verbindet, mediansagittal unterteilt.

VII. Stadium (Serie 28, Tafelfigur 5, 6).

Der Embryo ist bei einer Länge von $12 \mathrm{~mm}$ nur wenig weiter entwickelt als der eben beschriebene. Auch das Modell, das von dieser Serie angefertigt wurde, unterscheidet sich nur in Details von dem des Stadium VI.

Der Urogenitalhöcker ist in Form und Grösse fast unverändert geblieben. Doch tritt an seiner caudalen Seite zum ersten Male eine von der Basis bis zur Höckerspitze verlaufende Rinne auf, die, in der Medianebene gelegen, die Lage der Cloakenplatte, die an ihrem Grunde liegt, von aussen erkennen lässt. Diese Rinne ist unter dem Namen Urogenitalrinne beschrieben. Am tiefsten erscheint sie an ihrem proximalen Ende, wo von beiden Seiten die im früheren Stadium beschriebenen Wülste an sie heranreichen und mit den die Rinne begrenzenden Lippen verschmelzen. Gegen die Höckerspitze wird die Rinne allmählich seichter und verstreicht. 
Die Betrachtung der Serie erweckt den Anschein, als wäre die Rinne dadurch entstanden, dass die Mesodermlippen, die die Cloakenplatte einschliessen, von der Höckerbasis aus auseinanderzuweichen beginnen. Das dazwischen gelegene Epithel ist hellgefärbt, kernarm und scheint in Abstossung begriffen zu sein. Doch betrifft dieser. Degenerationsprozess nur die äussersten Partien der Cloakenplatte. Die central gelegenen Anteile weisen keinerlei Veränderung auf. Ungefähr von der Mitte der Cloakenplatte bis zu ihrem Ende an der Höckerspitze ist die Cloakenplatte vollständig' intakt.

Die Analregion ist gegenüber dem Modell von Stadium VI unverändert geblieben.

Der Sinus urogenitalis zieht von der Cloakenplatte in einem leichten cranialconcaven Bogen dorsalwärts. Er stellt ein schlauchförmiges Gebilde vor, das in craniocaudaler Richtung breitgedrückt ersçheint und sich von der Cloakenplatte aus allmählich verbreitert. Seine grösste Breite erreicht er in der Höhe der Ureterenmündung. An der oralen Fläche desı Sinus urogenitalis verlaufen zwei längsgestellte Epithelfalten. Die caudale Fläche ist leicht gehöhlt. In sie münden ein wenig caudal und medial von den Ureterenmündungen die Urnierengänge. Die Cloakenhörner der früheren Stadien sind fast vollständig in die Blasenanlage aufgenommen, sind aber immerhin noch in den leicht trichterförmigen Ureterostien zu erkennen. Ihnen verdankt die Blasenanlage an dieser Stelle ihre grösste Breite.

Ungefähr in der Höhe der Ureterostien ändert das ganze Gebilde Richtung und Gestalt. In einem beinahe rechten Winkel sitzt hier dem Sinus urogenitalis und dem caudalen Teil der Blasenanlage der craniale Teil auf. Dieser zieht parallel zur ventralen Leibeswand nach aufwärts und biegt in Nabelhöhe als Urachus wieder scharf um. 
Die Entwickelungsgeschichte des Urogenitalsystems beim Maulwurf. 467

Die Gestalt dieses Teiles der Blasenanlage ist weniger flach als der Sinus urogenitalis. Zwei hohe, an seiner dorsalen Wand verlaufende Epithelfalten, die dem Querschnitt des Gebildes die Gestalt einer plumpen Mondsichel geben, scheinen ihm eine grössere Ausdehnungsmöglichkeit zu verleihen. Der ganze Teil ist in eine dicke, dichte Mesodermmasse eingebettet.

Der Urachus ist in diesem Stadium ein dickwandiges Rohr mit engem Lumen und kreisförmigem Querschnitt.

VIII. Stadium (Serie 14, Tafelfigur 7, 8).

Der Embryo hat eine Länge von 17,5 mm.

Der Urogenitalhöcker ist bedeutend gewachsen und hat dabei seine Richtung geändert. Er steht jetzt als breiter, plumper Zapfen beinahe rechtwinklig von der Bauchwand ab. An seiner Basis wird er von den bereits beim. VI. Stadium beschriebenen Wülsten umgeben. Diese Wülste, die ursprünglich als paarige Gebilde imponierten, haben sich indessen auf die orale Seiter des Urogenitalhöckers fortgesetzt und sind hier ohne Grenze ineinander übergegangen. Auch an der caudalen Seite haben sie sich zusammengeschlossen, doch ist hier die Vereinigungslinie durch eine schwache Furche angedeutet. Das ganze Gebilde erscheint jetzt als ein Ringwulst, der die Höckerbasis umgibt. Er ist, von der vorderen Bauchwand durch eine scharfe Furche getrennt, am breitesten an der oralen, am schmalsten an der caudalen Seite des Höckers.

Dic Urogenitalrinne hat sich vertieft. Sie reicht jedoch nicht mehr von der Höckerspitze bis an seine Basis, sondern nur mehr bis zur distalen Grenze des Ringwulstes. Der Ringwulst hat also durch seine Vereinigung die Genitalrinne und mit ihr die Cloakenplatte von dem Perineum abgedrängt. Die Rinne endigt proximal in einem annähernd rautenförmigen Grübchen und wird, wie beim früheren Stadium, gegen die Höckerspitze seichter. 
Die Cloakenplatte hat sich in ihrem distalen Anteil nicht geändert. Ihr proximaler Teil ist durch' das Schliessen des Ringwulstes von ঐder Oberfläche des Urogenitalhöckers in die Tiefe gedrängt worden.

Der Sinus urogenitalis, der noch im vorigen Stadium einen cranialconcaven Bogen darstellte, hat wohl infolge der Änderung der Lage des Urogenitalhöckers auch eine Richtungsänderung erfahren. Sein schmaler, distaler Anteil bildet mit der Cloakenplatte einen cranialconvexen, der breite proximale Teil einen cranialconcaven Bogen. Wo die beiden Krümmungen ineinander übergehen, ragt jederseits ein kurzer Epithelspross caudalwärts, die Anlage der Cow pe r s'chen Drüsen.

Über der Mündung der Urnierengänge ist der Sinus urogenitalis durch eine leichte Einschnürung von der Blasenanlage abgegrenzt; ebenso ist eine ähnliche Einschnürung zwischen dem caudalen und dem cranialen Blasenteil zu bemerken, die noch dadurch besonders betont ist, dass der craniale Anteil der Blasenanlage dilatiert ist und am Querschnitt fast kreisförmig erscheint.

Zwischen den Mündungen der Ductus Wolffi haben die M üllerschen Gänge jetzt den Sinus urogenitalis erreicht und enden an seiner Hinterwand mit einer kolbenförmigen Anschwellung.

Der schwache Epithelstreifen, der nach der vollständigen Teilung der Cloake als Überrest der Cloakenplatte den Anus mit dem Urogenitalhöcker verbindet, zeigt ungefähr in der Mitte seines Verlaufes einen kleinen Spross, die Anlage der Analdrüse.

Beiläufig will ich bemerken, dass das knorpelig angelegte Becken in diesem Stadium durch eine ventrale Knorpelspange zu einem. Ring geschlossen ist; diese Spange, die auch in den weiteren Stadien noch zu sehen ist, geht später zugrunde. Beim erwachsenen Tier wird der Beckenring durch einen ligamentösen Apparat geschlossen. 
Die Entwickelungsgeschichte des Urogenitalsystems beim Maulwurf. 469

Die Durchsicht der Serie ergibt folgendes:

Der Unogenitalhöcker ist von einer dichten; kernreichen Mesodermmasse durahzogen, die, cranial von der Cloakenplatte gelegen, von der Spitze des Höckers bis zu der beschriebenen knorpeligen Symphyse zieht und sich hier in zwei Schenkel spaltet, die den Schambeinästen angelagert ein Stï̈ck analwärts reichen. Diese Mesodermmasse ist, soweit sie im Höcker liegt, von zahlreichen Blutgefässen umgeben. Sie stellt die Anlage des Phallusgerüstes vor. Von der Bauchwand zicht jederseits ein dünner Muskelstreifen gegen sie hin (Musc. levator penis).

Die Urogenitalrinne zeigt dasselbe Verhalten wie bei der zuvor beschriebenen Serie; der Zellzerfall ist besonders in dem rautenförmigen: Grübchen am basalen Ende der Rinne sehr deutlich.

Das Epithel des Sinus urogienitalis biesteht aus einer hohen Schicht von hellen grosskernigen Zellen. Von diesen hebt sich sehr deutlich das Epitnel der Müllerschen Gänge $a b$. Ihr distales, erweitertes Ende liegt der dorsalen Wiand des Sinus urogenitalis 'an, ohne in ihn zu münden. Eine auffallend grosse Anzahl von Kernteilungsfiguren in diesem Endteil der M ü $1 \mathrm{l}$ e r schen Gänge lässt auf eine grosse Wachstumstendenz dieser Teile schliessen.

Die Partie der Blasenanlage, in dio die Ureteren münden, zeigt mehrreihiges Epithel und ist.von Bindegewebszellen umgeben. Der craniale Teil der Blase wird hingegen von mehreren Lagen zirkulär und longitudinal verlaufender Muskelfasern umschlossen.

Der Anus ist noch durch die Analmembran verschlossen.

IX. Stadium (Serie 43, Tafelfigur 9).

Der Embryo ist $23 \mathrm{~mm}$ lang, seine Kopflänge beträgt $11 \mathrm{~mm}$. 
An dem Modell, das nach diesem Stadium angefertigt wurde, sieht man den Urogenitalhöcker, dessen craniale Partie zwecks besserer Übersicht nicht mitmodelliert wurde, caudalwärts gekrümmt. Seine proximale Hälfte ist von dem stark vorgewachsenen Ringwulst bedeckt. An der Caudalseite des Höckers zeigt sich wieder dasselbe Grübchen mit der anschliessenden Genitalrinne, die aber durch das Distalrücken des Ringswulstes stark verkürzt erscheint. Das Grübchen ist viel tiefer geworden und ist sogar als kurzer Gang proximalwärts in den Höcker zu verfolgen.

Im Innern des Höckers ist eine neue Bildung aufgetreten. Von der distalen Grenze des Wulstes her ragt eine Ectodermlamelle in das Höckermesoderm vor. Diese Lamelle entspringt an der distalen Grenze des Wulstes, und zwar in ihrer ganzen Circumferenz. Dort, wo der Wulst an der caudalen Höckerseite das mehrfach erwähnte Grübchen und damit die Cloakenplatte begrenzt, tritt die Lamelle mit dieser in innige Verbindung. Ihre Zellen unterscheiden sich in nichts von denen des Ectoderms und vereinigen sich ohne Grenze mit denen der Cloakenplatte. An dieser Stelle ist die Lamelle sehr niedrig, sie gewinnt aber lateral davon an Ausdehnung und erreicht an der oralen Seite desi Höckers in der Mittellinie ihre grösste Höhe.

Ihre Verlaufsrichtung ist dabei eine solche, dass die Lamelle in derselben Ebene liegt, wie das Integument des schmalen, distalen Höckeranteils. Ein Schema, das einen Mediansagittalschnitt durch den Genitalhöcker dieses Stadiums darstellt (Text. figur 12), zeigt uns dieses Verhalten ebenso wie ein Transversalschnitt, der gleichzeitig den dünnen, distalen und den starken, proximalen Höckeranteil getroffen hat (Schnitt a, Textfigur 13). Die Lamelle ist die Glandarlamelle Fleis chmanns. Was innerhalb von ihr gelegen ist, wird zum Penis, beziehungsweise Clitoris, was ausserhalb liegt, wird zum Prä- 


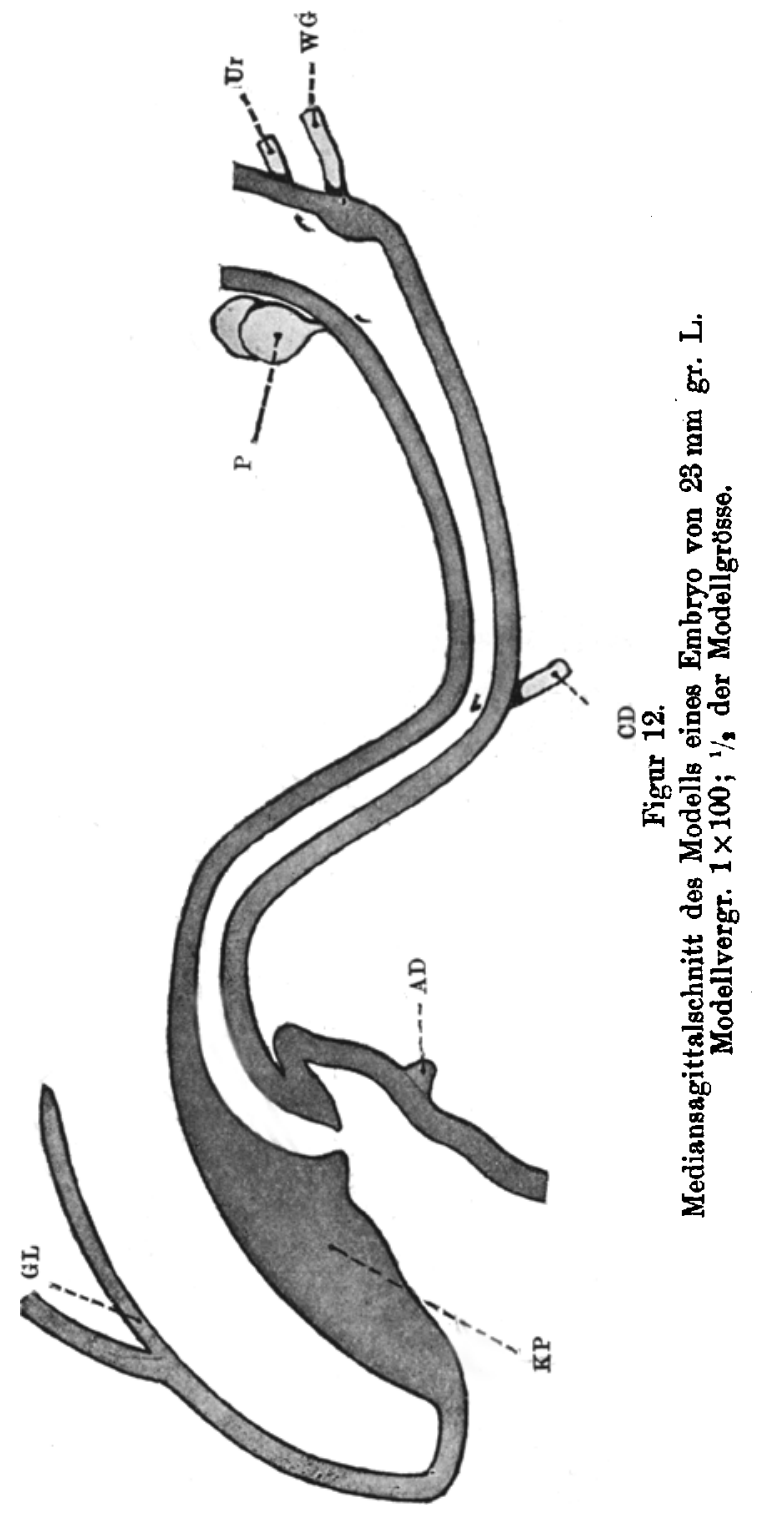


472 .

FRANZ C. KRASA,

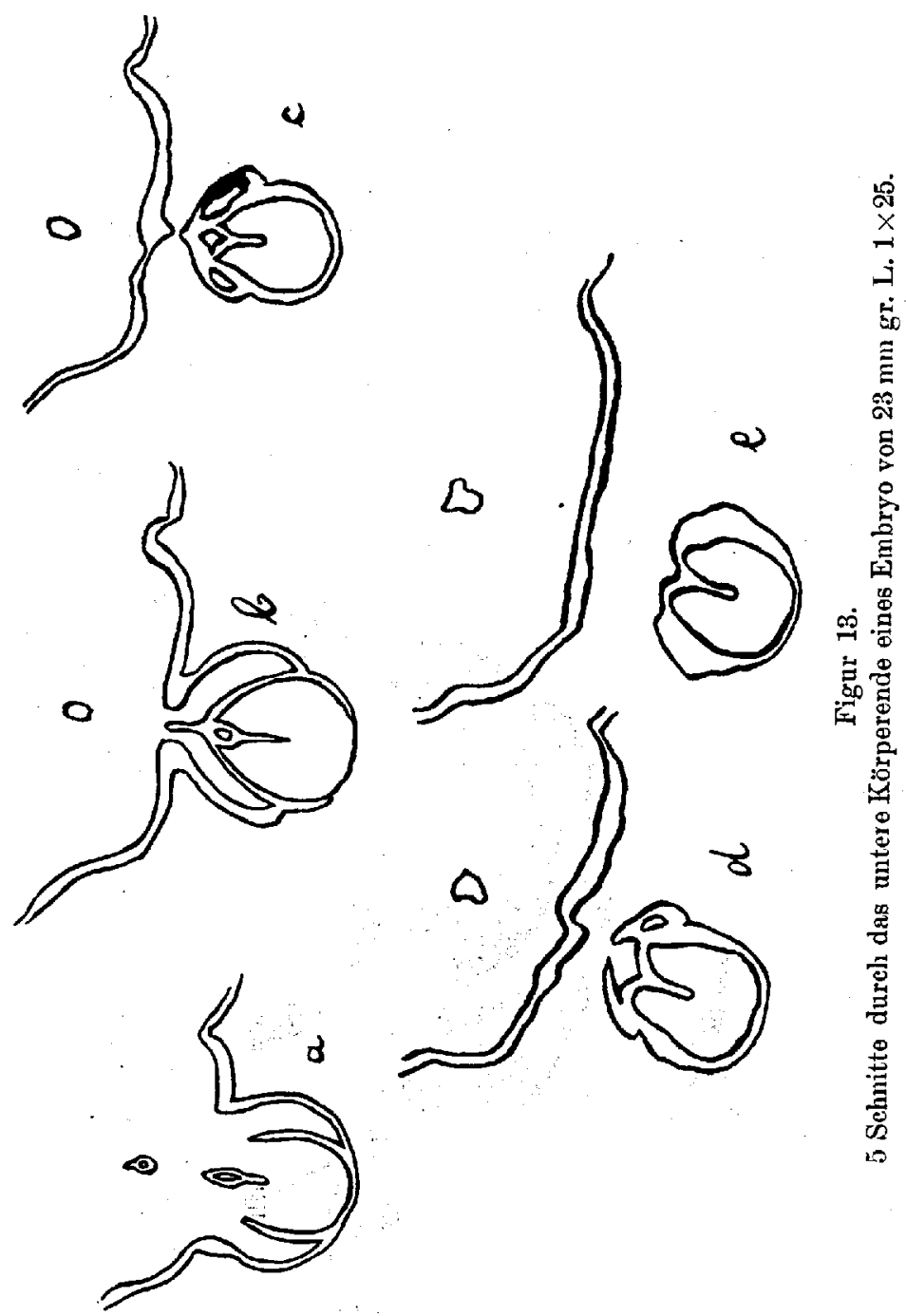


Die Entwickelungsgeschichte des Urogenitalsystems beim Maulwurf. 473

putium, weshalb die Falte, zu der sich der Ringwulst jetzt entwickelt hat, als Präputialfalte bezeichnet wird.

Der Sinus urogenitalis ist viel kräftiger S-förmig gekrümmt. Das Endstück der Ausführungsgänge der C o w p e r schen Drüsen ist an der beim vorigen Modell beschriebenen Stelle zu sehen. Dio Drüsenanlage selbst ist, wie die Durchsicht der Serie ergibt, bedeutend in die Länge gewachsen und trägt an ihrem caudalen Ende jederseits eine kolbige Verdickung.

An lder oralen Seite des Sinus zeigt das Modell vier frontal nebeneinanderstehende kugelförmige Gebilde, die mit je einem kurzen Stiel der Sinuswand aufsitzen. Es sind die Anlagen der vier Prostatalappen des erwachsenen männlichen Tieres.

Daś Ende der vereinigten $M$ ü 11 e r schen Gänge liegt etwas tiefer als die Urnierengänge.

Der craniale Teil der Blasenanlage steht mit dem caudalen, in den die Ureteren münden, durch einen frontal eingestellten Spalt in Kommunikation.

Rechts und links von dem beim vorigen Stadium beschriebenen Analdrüsenspross haben sich zwei neue Zellsprossen gebildet, die auch der Analdrüse angehören.

Der Enddarm zeigt zahlreiche Falten. Die Stelle, wo er auf dem Ectoderm mündet, ist leicht vorgewölbt. Seine Offnung ist am Modell nicht kenntlich, da sie noch durch nekrotisierende Zellmassen, Reste der Analmembran, verstopft ist.

Die Betrachtung der Serie ergibt noch folgende Details:

An der Spitze des Höckers ist die Cloakenplatte noch in unveränderter Gestalt erhalten. Die basale Cylinderzellenschicht der Haut geht kontinuierlich auf die Platte über. Das starke Epithe] des Höckers verhornt an der Oberfläche in geringem Masse.

Wenige Schnitte weiter proximal ist bereits die Genitalrinne angedeutet (Schnitt e). Ihr Entstehen wird, wie aus den Schnitten ersichtlich, durch zwei Faktoren bedingt: erstens 
durch das Auseinanderweichen der die Rinne begrenzenden Mesodermlippen, zweitens durch die Degeneration und $\mathrm{Ab}$ stossung der oberflächlichen Epithelschichten.

Schon der nächste Schnitt (Schnitt d) zeigt diese Rinne nur mehr als Boden eines Rohres, dessen Decke von dem über die Rinne vorgewachsenen Ringwulst beigestellt wird, so dass dieses Rohr also caudal und lateral von der Cloakenplatte, oral aber von der Glandarlamelle und jener dünnen Epithelschicht begrenzt wird, welche die Lötstelle des früher halbmondförmigen, jetzt ringförmigen Wulstes anzeigt. Das Rohr ist noch ein Stück weit proximal in den Höcker zu verfolgen. Man bemerkt dabei, dass sein Lumen durch ein Weiterauseinanderweichen der Wände der Cloakenplatte so in diese hineinrückt, dass die Glandarlamelle schliesslich keinen Anteil mehr daran hat, mit ihm aber doch in ihrer ganzen Ausdehnung durch einen dünnen Epithelstreifen verbunden bleibt.

Das Rohr, welches die Anlage der Urethra darstellt, geht am' proximalen Ende des Ringwulstes in den Sinus urogenitalis über. Auch an diesem ist der Beginn einer Lumenbildung zu bemerken; die central gelegenen Zellen beginnen zu degenerieren. Sie sind yiel schwächer gefärbt und man sieht zahlreiche zerfallende Kerne.

Das caudale Ende der $M$ üllerschen Gänge liegt so wie beim vorher beschriebenen Embryo der caudalen Wand des Sinus urogenitalis an.

Die in der Beschreibung des vorigen Modells erstmals erwähnte Knorpelspange ist auch in diesem Stadium vorhanden. Sie ist aber im Gegensatz zu den anderen in diesen Schnitten vorkommenden Knorpeln eosinophil.

X. S tadium (Serie 31).

Das nächstgrössere Stadium wird durch einen weiblichen Embryo von $26 \mathrm{~mm}$ grösster Länge und $12 \mathrm{~mm}$ Kopflänge repräsentiert. 
Die Entwickelungsgeschichte des Urogenitalsystems beim Maulwurf. 475

Modelliert wurde nur der caudale Teil des Urogenitalhöckers. Das Modell zeigt den Ringwulst bedeutend vorgewachsen, so dass nur mehr ein kleiner Teil des Höckers freibleibt.

Die Offnung, die das' proximale Ende der Cloakenplatte bildet, ist dadurch wieder weiter von der Höckerbasis abgerückt, die Kloakenplatte weiter verkürzt.
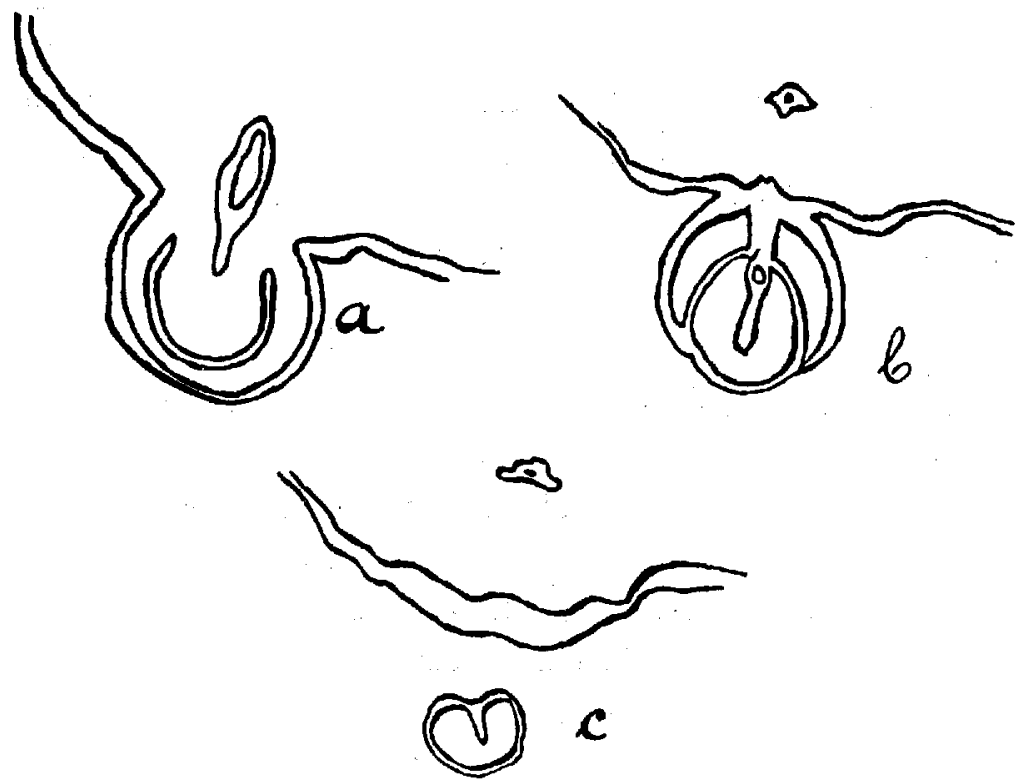

Figur 14.

3 Schnitte durch dąs untere Körperende eines Embryo von 26 mm gr. L. $1 \times 25$.

Die Serie zeigt folgendes (Textfigur 14):

Die Bildung der Urethra sowie das Vorwachsen des Ringwulstes yollziehen sich auch bei diesem Stadium in der vorher beschriebenen Weise.: Ebenso die Lumenbildung in der distalen Partie des Sinus urogenitalis. Dieser hat im allgemeinen noch dieselbe Form wie bei dem früher beschriebenen männlichen Embryo, ist aber kürzer und weiter. 
Die W olffschen Gänge sind in ihrem Wachstum sehr zurückgeblieben.

Die $\mathrm{M}$ ü1lerschen Gänge sind wieder in caudaler Richtung vorgewachsen. Ihr Verhalten gegenüber dem Sinus hat sich nicht geändert.

Die Anhangdrüsen, Prostata, Cow persche Drüsen und Analdrüsen, sind nur schwach ausgebildet.

Der Darm mündet auf einem kräftig entwickelten Höcker durch einen transversalen Spalt, der von verhornenden Ectodermzellen ausgekleidet ist, nach aussen. In der Tiefe des Spaltes füllen noch Reste der Analmembran das Darmlumen aus. Erst von idieser Stelle an proximalwärts wird der Analteil des Darmes von Entodermzellen gebildet.

XI. Stadium' (Serie 58).

Der Embryo ist ein Weibchen mit der grössten Länge von $34 \mathrm{~mm}$ und Kopflänge $15 \mathrm{~mm}$.

Es sind folgende Fortschritte zu konstatieren:

Der Ringwulst lässt nur mehr die Höckerspitze frei. An dieser hat sich die bleibende Öfnung der Urethra durch Auseinanderweichen des distalsten Stückes der Cloakenplatte gebildet (Textfigur 15). Der Sinusi urogenitalis hat sich stark ausgeweitet und ragt als mächtiger Hohlraum bis an den Höcker heran, wo er sich in die ein grosses Lumien aufweisende Harnröhre fortsietzt.

Alles andere hat sich gegenüber dem $X$. Stadium nicht wesentlich geändert.

Nur die M ülle r schen Gänge sind bedeutend in die Länge gewachsen. Sie ziehen-als ein durch ein dünnes sagittales Septum geteiltes Rohr, von reichlicher Mesodermmasse einge: hüllt, in mehreren Windungen unter der Convexität des Sinus urogenitalis weg und nähern sich der Abgangsstelle der Cow perschen Drüsen und damit dem Ectoderm (Textfigur 16). 
Der Anus liegt auf der Spitze einer kegelförmigen Erhebung.

XII. Stadium (erwachsenes Tier).

Männchen (Textfigur 17): Die Harnblase des erwachsenen Maulwurfs gliedert sich bei beiden Geschlechtern in zwei deut-
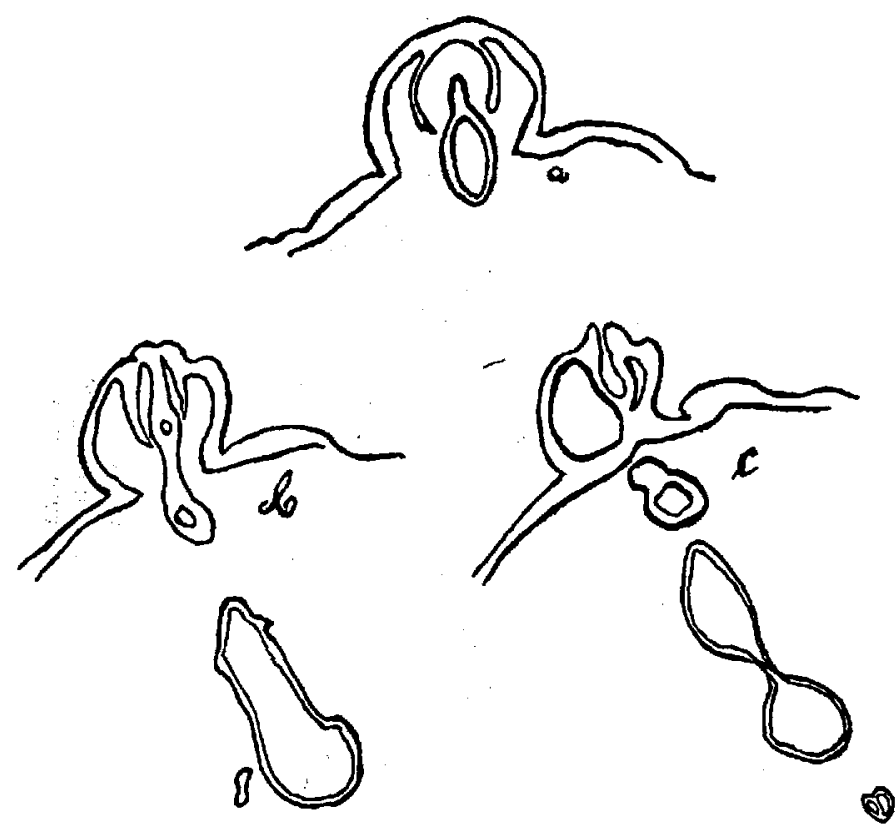

(9)

Figur. 15.

3 Schnitte durch das untere Körperende eines Embryo von $34 \mathrm{~mm}$. $1 \times 25$.

lich voneinander getrennte Abteilungen. Die craniale ist in kontrahiertem Zustande kugelförmig, mit einem Durchmesser von 6-8 $\mathrm{mm}$. Ihre Wand wird von Muskulatur gebildet, deren Verlauf durch das dünne Peritoneum deutlich sichtbar ist. Die Stärke der Wand beträgt bis zu $4 \mathrm{~mm}$, da die Blase in kontrahiertem Zustande kaum ein Lumen besitzt. Ist die Blase gefüllt, so erreicht sie an Grösse das doppelte und dreifache der 


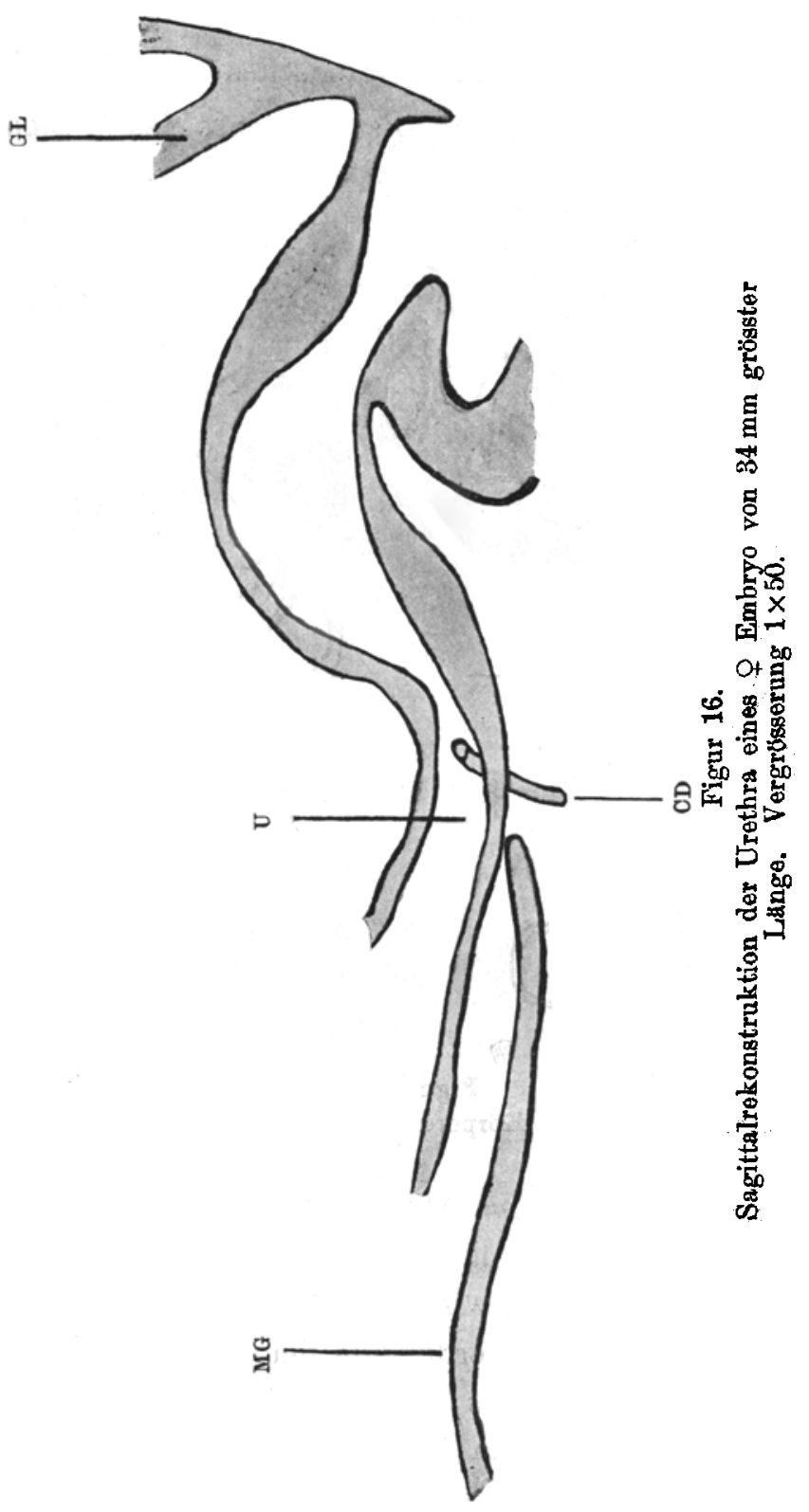


Die Entwickelungsgeschichte des Urogenitalsystems beim Maulwurf. 478

angegebenen Masse, die Wand ist dann entsprechend verdünnt, fast durchscheinend.

Der craniale Teil der Blase ist durch einen transversalen Spalt in Verbindung mit dem caudalen Teil. Dieser hat die Form eines kurzen Trichters. Seine Wände sind dünn, bestehen grösstenteils aus Bindegewebe und sind nicht dilatierbar. Diesen Teil der Blase, in den die Ureteren münden, kann man als Pars trigonalis dem cranialen Teil, dem Corpus vesicae oder Pars muscularis, gegenüberstellen. Durch eine kurze Urethra

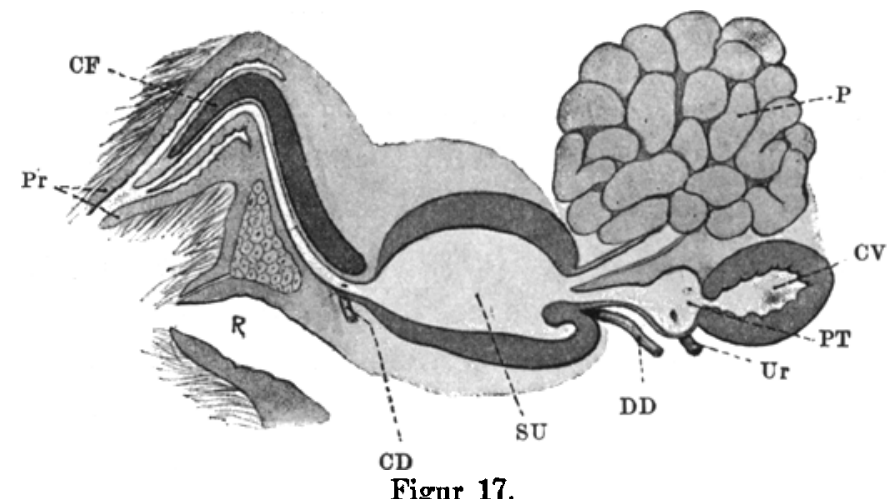

Schema eines Sagittalschnittes durch ein erwachsenes $\sigma^{7}$ Genitale. $1 \times 2$.

sensu strict. ist dieser Blasenteil mit dem Sinus urogenitalis in Verbindung.

Dieser stellt beim Männchen einen eiförmigen Hohlraum von ungefähr 10-12 mm Längs- und 5-7 mm Querdurchmesser vor. Sein proximales Ende ist durch eine quergestellte Falte in eine ventrale und eine dorsale Tasche geteilt. In der ventralen mündet die Urethra und die vier Ausführungsgänge der Prostata. Auf der Falte selbst die Vasa deferentia. Die dorsale Tasche wurde von Leukart irrtümlich als Vagina masculina beschrieben. Gross fand Reste der M üllerschen Gänge, also die Vagina masculina, zwischen den Mündungen 
der Vasa deferentia auf. Distalwärts verengt sich der Sinus allmählich und geht unmerklich in das' enge Rohr über, das als Urethra im weiteren Sinne bezeichnet werden kann. An dem Übergang zwischien dem weiten Teil des Sinus und dem engen münden die Ausführungsgänge der Cowperschen Drüsen. Der weite Sinusteil ist von einem kräftigen Ringmuskel umgeben, der proximal noch den dünnen Halsteil der Blase sowie die Vasa deferentia umigreift, distal bis über die Mündung der Glandulae Cowperi hinaus den Sinus bekleidet.

Die Urethra tritt unter den Schenkeln des Corpus fibrosum penis heraus und verläuft an dieses angeschlossen bis zu der Penisspitze.

Die Hoden liegen beiderseits der Harnblase der vorderen Bauchwand an. Sie sind in ihrer Grösse entsprechend den verschiedenen Brunstperioden sehr variabel, treten aber nie aus der Bauchhöhle heraus. Im: Stadium der Turgescenz wölben sie an der Bauchwand einen seichten Kremastersack vor, über dessen Anatomie $\mathrm{K}$ a u dern berichtet hat. Ein konstanter, in seiner Grösse sehr variabler Anteil des Kremastersackes enthält nur den Nebenhodensch'wanz. Aus dieser Tasche zieht der Ductus deferens gegen die craniale Wand des Sinus urogenitalis.

Ventral von der Harnblase ist die Prostata gelegen, die auch in ihrer Grösse beträchtlichen Schwankungen unterworfen ist. Diese Grössendifferenzen betrugen auch an Tieren, die am selben Tag getötet wurden, mehr als $15 \mathrm{~mm}$. Ist die Drüse klein, also in Ruhe oder nach der Entleerung, so ist sie nicht grösser als die Harmblase. Ist sie gross und mit Sekret gefüllt, so füllt sie, an beide Hoden heranreichend, mit diesen die ganze untere Hälfte des Bauchraumes aus. Die Drüse wird durch ein makroskopisch erkennbares Konvolut von langen Drüsengängen gebildet, die ebenso wie die Drüse selbst eine wechselnde Stärke besitzen. Sie werden von ganz lockerem, 
dünnen Bindegewebe umgeben. Die Drüse ist von Peritoneum üblerzogen. Sie ist präparatorisch unschwer in vier nebeneinander liegende Lappen zu trennen, deren jeder durch einen besonderen Ausführungsgang in den Sinus urogenitalis mündet.

Die C ow p e r schen Drüsen liegen ausserhalb des Beckens, lateral von dem Crus penis, bedeckt von dem konstanten Teil des Kremastersackes. Sie haben längliche Gestalt und sind an der Spitze umgebogen. Ihr langer dünner Ausführungsgang kreuzt das Crus penis seiner Seite und mündet in die Urethra. Die Drüse ist azinös gebaut und von quergestreifter Muskulatur umgeben.

Der Penis, dessen Körper ungefähr $3 \mathrm{~cm}$ lang ist, liegt zum grössten Teil unter der Hant. Sein Gerüst wird durch ein Corpus fibrosum gebildet, welches mit zwei kolbig verdickten Schenkeln am Becken entspringt, die sich nach kurzem Verlauf zum Corpus penis vereinigen. Dieses liegt in der Medianebene der Bauchdecke an, biegt hakenförmig um und verläuft dann in caudaler und ventraler Richtung. An seiner Spitze trägt es ein zartes Os penis. Es ist wie das distale Ende des Corpus fibrosum von cavernösem Gewebe umgeben. Das distale Ende des Penis ist nicht wie der Körper rund, sondern lanzettförmig. Ein Musculus levator penis ist vorhanden. Der Vorhautsack reicht bis an die Krümmung des Penis heran.

Die Vorhaut selbst bildet einen 3-4 mm hohen Kegel, der in analer Richtung aus der vorderen Bauchwand vorspringt.

Durch den Damm davon getrennt steht ein ähnlicher, kleinerer Kegel, der an seiner Spitze die Analöffnung trägt. Zwischen den beiden Erhebungen liegen unter dem Integument die Analdrüsen, deren Ausführungsgänge an der Spitze des Kegels neben dem Anus münden. Es sind drei gesonderte Drüsen zu unterscheiden, eine mittlere unpaare und zwei lateral davon gelegene paarige. Die dünne, 'die Drüsen bekleidende Muskelschicht strahlt in die den After umgebende Muskulatur aus. 
Uber die Unterschiede im Bau und Sekret dieser Drüsen siehe Gross, Archiv f. mikr. Anatomie, Bd. 66.

Durch die Gruppierung dieser Drüsen, sowie der Cowper schen Drüsen, der Penisschenkel und der Cauda epididymis um den After, entstehen rechts und links von diesem mächtige Wülste, die besonders zur Brunstzeit leicht die Männchen von den Weibchen unterscheiden lassen.

In der Illustration (Tafelfigur 10) ist das Integument der Anourogenitalregion caudal umgeklappt. Der Penis ist durch-

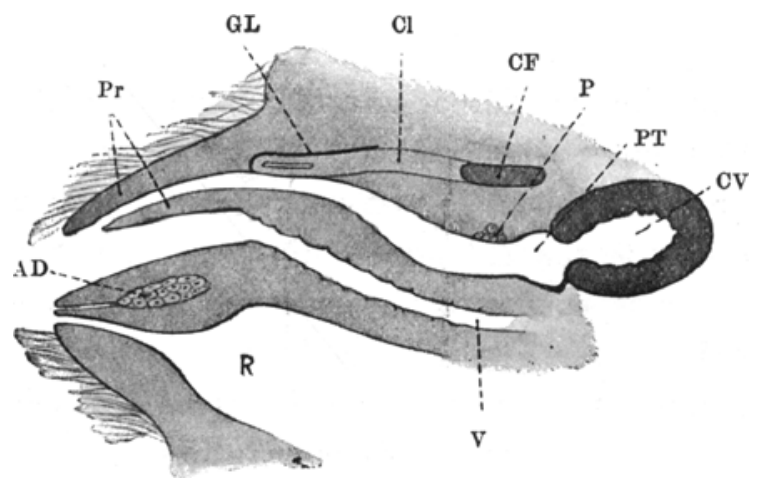

Figar 18.

Schema eines Sagittalschnittes durch ein erwachsenes $O+$ Genitale. $1 \times 2$.

schnitten; rechts ist auch der Kremastersack abgetragen, um die Cowpersche Drüse besser sichtbar zu machen.

Weibchen (Textfigur 18): Die Blase des weiblichen Tieres entspricht, wie bereits bemerkt, in allen Punkten genau der des Männchens. Auch der Sinus urogenitalis weist alle beim Männchen beschriebenen Teile auf. Nur ist er viel kleiner und kürzer als der des Männchens. Der proximale Teil des Sinus ist kaum weiter als der distale, trotzdem aber auch an seiner Muskelbekleidung deutlich kenntlich. Die Prostata ist rudimentär, mikroskopisch immer, häufig auch makroskopisch nachweisbar. Ebenso ist die Cowpersche Drüse und die Analdrüse nur wenig entwickelt. 
Die F.ntwickelungsgeschichte des Urogenitalsystems beim Maulwurf. 483

Die äusseren Genitalien sind den männlichen sehr ähnlich. Das Praeputium clitoridis ist fast so gross wie das des Penis. Doch reicht die Glans nur wenig hinein. Das Corpus fibrosum hat einen kurzen Schaft und zwei lange Schenkel. Ein 0 s clitoridis und ein Corpus cavernosum vervollständigen das Gerüst der Clitoris.

Der Uterus ist zweihörnig. Die Vagina mündet bei geschlechlsrcifen Tieren in einem transversalen Spalt unmittelbar an der caudalen Grenze des Präputiums. Bei einem anfangs Mai getöteten jungen Tier fand ich die Vagina vollkommen atretisch, bei einem anderen, das Endę Mai getötet wurde, das Lumen eben im Durchbruch, ein Verhalten, das schon 0 w e $n$ beschrieben hat, spätere Autoren aber nicht bestätigen konnten.

Der Anus ist ebenso geformt wie beim Männchen.

\section{Die Entwicklung und Teilung der Cloake und der Anourogenitalhöcker.}

Eine kurzgefasste zusammenhängende Darstellung der Entwickelungsvorgänge, die die Bildung und Aufteilung der Cloake bewirken, sei im folgenden Resümee gegeben: Die weite Endkammer des Darmes, die den ganzen Raum zwischen Chorda dorsalis und ventraler Leibeswand einnimmt, und mit dieser durch eine kurze breite Ecto-Entodermverbindung, die Cloakenmembran, zusammenhängt, ist die Vorstufe der Cloake. Mit ihr hängt ventral die als mächtige Blase vorragende Allantois zusammen.

Als Cloake sensu strictiori kann man diesen Raum erst dann bezeichnen, wenn die Urnierengänge ihn erreicht haben und in. ihn münden (siehe das zweite Stadium). Die Cloake ist gleichzeitig in transversaler Richtung flachgedrückt und von der Chorda dorsalis abgedrängt worden. Die innige Beziehung zur ventralen Rumpfwand hat sie beibehalten; die 
Cloakenmembran ist länger geworden. In ihrer Nähe münden die Urnierengänge mit kleinen, trichterförmigen Ausweitungen. Durch Differenzierung des caudalen Teiles des früher einheitlichen Hohlraumes bildet sich an der dorsocaudalen Seite der Cloake der Schwanzdarm als ein weites dünnwandiges Rohr. Von diesem Stadium an sind es hauptsächlich die ventralen Teile der Cloake, die an den weiteren Entwickelungsvorgängen teilnehmen, während die dorsialen teils ohne ihre Gestalt oder ihre Lage im wesentlichen zu ändern, weiterwachsen, wie der Darmteil der Cloake, teils zugrundegehen wie der Schwanzdarm. Es sind dementsprechend, wie ich es ja auch in der Beschreibung hervorgehoben 'habe, Kernteilungen hauptsächlich in dem ventralen Teil der Cloake und in dem diesem Teil benachbarten Mesioderm zu beobachten.

Es sind zwei voneinander getrennte Wachstumsvorgänge zu unterscheiden. Einerseits weiten sich die oralen Teile der Cloake, wo Allantoisgang und Urmierengänge münden, zur Harnblasenanlage und den Cloakenhörnern auș. Die Mündungstrichter der Unnierengänge werden dabei auch ausgeweitet und in die Blasenwand einbezogen, so dass dann die Urnierengänge getrennt von den Ureteren, die aus ihrer dorsalen Wand hervorgesprossen sind, in die Blasenanlage münden. Andererseits aber nimml das Mesoderm, das oral von der Cloake gelegen ist, in craniocaudaler Richtung stark an Masse zu und bildet dadurch erstens den aus der ventralen Rumpfwand unterhalb des Nabels' vorwachsenden Anourogenitalhöcker, zweitens aber eine frontal in das Lumen der Cloake von ihrer oralen Wand her einwachsende Falte, die den Sinus urogenitalis vom Darm trennt, schliesslich das Ectoderm erreicht und den Damm bildet. Es ist selbstverständlich, dass das diesen neuauftretenden Bildungen angehörige Entoderm ebenfalls' aktiv mitwachsen muss.

Was die Bildung des Anourogenitalhöckers betrifft, so ist es meines Erachtens genügend oft und klar gesagt worden, dass 
Die Entwickelungsgeschichte des Urogenitalsystems beim Maulwurf. 485

er, wenigstens bei den Säugetieren, unpaarig entsteht und dass die Cloakenplatte sich gleichzeitig mit ihm ausbildet. Auch ist die Kritik der Literatur über diese Streitfrage in A n d e r s s on s Arbeit eine so ausführliche, dass ich nichts hinzuzufügen habe.

Die Frage nach der Aufteilung der Cloake hat zahlreiche Bearbeiter gefunden, deren Ansichten sich in zwei Hauptgruppen teilen lassen. Dabei sind die objektiven Befunde bei allen Autoren, die Fleis chmannsche Schule ausgenommen, beinahe dieselben. Alle beschreiben eine frontale Scheidawand, die durch ihr Herunterwachsen die Teilung der Cloake besorgt. Nur über die Art des Herunterwachsens sind sie verschiedener Meinung. Die Hauptvertreter der differenten Theorien sind Rathke urd Tourneux. R athke beschreibt zwei seitliche Falten, durch deren Vereinigung das frontale Septum zustande kommen soll. Tou r n e u x hingegen und seine Anhänger lassen das Septum selbst als eine frontal gestellte Falte caudalwärts rücken. Keibel, der die gegnerischen Ansichten $R$ athkes und Tourneux zu vereinigen versucht, und Disse, der die herunterwachsende Scheidewand mit dem halbmondförmigen Rand beschreibt, dürften der Wahrheit am nächsten gekommen sein. Einen eigenen Standpunkt nimmt die Schule F lei s ch. manns dieser Frage gegenüber ein.

F l e i s chmann selbst bringt in Nummer IV seiner Morphologischen Studien über Cloake und Phallus der Amnioten auf Tafel $X$ zwei Median-Sagittalschnitte durch Maulwurfemibryonen (Textfigur 19), von denen Figur 1 die Teilung der Cloake in ihrem Beginne zeigt. Der Darmsattel beginnt einzuschneiden und der Höcker ist als leichte Vorwölbüng der oral von der Cloakenplatte gelegenen Mesndermmasse zu erkennen. Figur. 2 auf derselben Tafel zeigt den Teilungsprozess nahe seinem Ende. Der Schnitt entspricht dem von mir als Textfigur 9 beschriebenen. Fleischmann hat zwar keine Zwischenstadien gesehen, tritt aber entschieden gegen 
Rathkes Theorie auf. Seiner Meinung nach wird die Mündung des Darmrohres in irgend einer Weise von der oralen Wand der Cloake an die dorsale verschoben, doch erscheint ihm die Meinung von Tourneux sehr plausibel, dass die Stelle der oralen Urodeumwand, welche im Längsschnitt Figur 1 zungenförmig zwischen dem Lumen des Enddarmes und des Allantoisstieles liegt, durch starkes Wachstum caudal ausgedehnt werde, bis der Zustand der Figur 2 erreicht ist. Dies

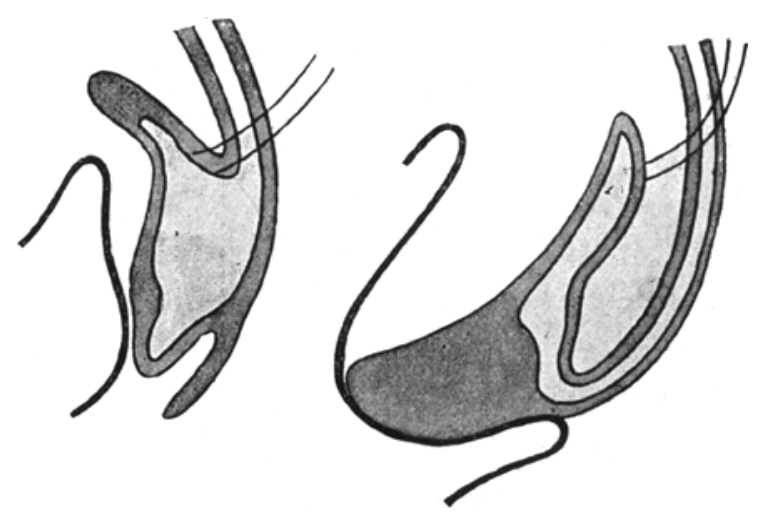

Figur 19.

Sagittalschnitte durch 2 Maulwurfsembryonen nach Fleischmann, Morph. Studien IV.

bedeute aber nichts anderes als eine stilistische Fassung für die Erkenntnis von Ähnlichkeiten und Unterschieden zwischen den beiden Figuren; niemand habe den Abgliederungsvorgang gesehen.

Dimpfl, der in der zehnten Arbeit des obenerwähnten Cyklus die Teilung der Cloake des Meerschweinchens behandelt, hat zwar die seilichen Falten gesehen, deutet sie aber anders als Retterer und Keibel es getan haben. Diese Falten bilden nach ihm nur den Grenzrand zwischen dem ventralen aufgeblähten und dem dorsalen schmalen Teil der Cloake. Die Anwesenheit einer frontalen Scheidewand leugnet er schlechter- 
Die Entwickelungsgeschichte des Urogenitalsystems beim Maulwurf. 487

dings, obzwar er wieder zugibt, dass „das, was $\mathrm{K}$ e i bel und $D$ is se an den Längsschnitten frontale Scheidewand nannten, einer Falte sehr ähnlich sehe". Er macht das Zusammenwirken komplizierter Wachstums- und Resorptionsvorgänge für die Durchführung der Teilung verantwortlich. Das von ihm beschriebene Wachstum der oralen Partien des Sinus urogenitalis beruht zwar 'zweifellos auf richtigen Beobachtungen. Doch ist, wie auch Andersson ausgeführt hat, von einer Resorption eines so grossen Anteils, wie ihn Dimpfls ,Caudalkammer“ darstellt, absolut nichts zu sehen. Dimpfl vergisst auch mitzuteilen, warum das Epithel der Caudalkammer ventral, wo aus der Cloake Sinus urogenitalis wird, ein anderes wird als das dorsale, in dem man deutlich Darmepithel erkennt. Ein wichtiger Umstand aber, der gegen die Theorie Dimpfls spricht, ist die Tatsache, dass Dimpfl zwar die Unrichtigkeit der früheren Ansichten beweist, zur Unterstützung seiner Behauptungen aber nur die subjektiv gefärbte Beschreibung seiner Modelle bringt, obzwar er zugibt, dass an diesen sowohl eine Bildung vorzufinden ist, die den von $\mathrm{R}$ et te re $\mathrm{r}, \mathrm{K}$ ei ble $l$ u. a. beschriebenen Falten als auch eine solche, welche der frontalen Scheidewand Disises, dem éperon périneal nach T o u r n e u sehr ähnlich sieht.

Endlich komme ich zu einer Kritik der von A nde r sis on aufgestellten Theorie. Unstreitig hat dieser Autor das Verdienst zum erstenmal ausgesprochen zu haben, dass die Teilung der Cloake mit der Bildung des Anourogenitalhöckers zusammenhänge. Allerdings geht er zu weit, wenn er behauptet, „die Teilung beruht ganz einfach auf der Ausbildung des Anourogenitalhöckers und dem Hineinrücken der Cloake in denselben“".

Seine Darstellung ides Vorganges ist kurz gefasst folgende: Das Auswachsen des Höckers geschieht durch eine einheitliche Vorstülpung der ganzen präcaudalen, postumbilikalen Mesodermpartie biesonders von den am meisten oral gelegenen Teilen 
aus. Durch Emporwachsen der basal oralen Teile werden allmählich die Gewebe des Höckers von der oralen nach der caudalen Seite verschoben und die Cloake, die sich anfangs durch den ganzen Höcker erstreckt, erhält eine median caudale Lage, andauernd durch die Platte, mit dem Ectoderm vereinigt. Entgegen der Fleis chmannschen Ansicht, dass der Auswuchs der hohen Platte (= Cloakenplatte) durch eine lebhafte Zellteilung innerhalb der frühzeitigen niederen Platte (= Cloakenmembran) geschieht, ist A n d e rs s on der Meinung, dass die ventrale Partie der Cloake von den anderen anwachsenden Geweben mitgezogen wird und die hohe Platte durch Zusammenpressung der Wände der Claake entstehe. Die Teilung der Cloake beruht hauptsächlich auf der veränderten Form und Lage derselben. Der früher länglich ovale Sack verändert sich mit dem Einrücken des ventralen Teiles desselben in den Höcker zu einer sich in dorsoventraler Richtung erstreckenden bogenförmigen Bildung, deren hintere Wand längs der caudalen Medianlinie des Höckers zu liegen kommt. Die orale Wand oder der Darmsattel wird nun auch caudalwärts gezogen und verschmilzt an der Schwanzbasis mit der hohen caudalen Wand (= Platte). Indessen dringt der mesodermale Sattel andauernd rückwärts. Durch den Druck, welcher dabei auf die Platte ausgeübt wird, wird diese resorbiert und das Mesoderm dringt bis zum Ectoderm vor. Damit ist der Damm gebildet und die Teilung der Cloake vollendet. Nur in der allerersten und allerletzten Phase des Teilungsprozesses kann man von einer Scheidewand sprechen, die in die Cloake hineinwächst ${ }^{1}$ ). Zur Veranschaulichung seiner Ansicht bringt er das in Figur 20 wiedergegebene Schema.

Soweit A nderss on s Ausführungen die Entwickelung des Höckers 'betreffen, sind sie wohl richtig. Sicher wird der Höcker durch das Anwachsen der oral von der Cloake gelegenen Meso-

1) Wörtlich zitiert. 
J)ie Entwickelungsgeschichte des Urogenitalsystems beim Maulwurf. 489

dermmassen vorgestülpt. Dabei wird selbstverständlich auch die im Niveau des Ectoderms gelegene Cloakenmembran aus ihrer Lage gebracht. Die unmittelbar an die Membran anschliessenden Seitenwände der Cloake verschmelzen miteinander, ein Vorgang, den man sich aber nicht durch ein Zusammengepresstwerden der Wände erklären darf. Offenbar geschieht diese Verschmelzung durch eine lebhafte Proliferation der Epithelien, die ja durch die Anwesenheit der Mitosen in früheren Stadien genügend bewiesen erscheint.

Auch der Zusammenhang zwischen der Ausbildung des Höckers und der Teilung der Cloake ist von Andersson

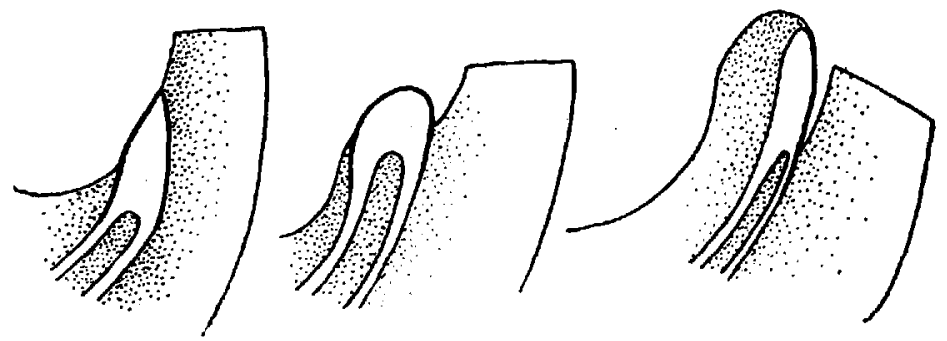

Figur 20.

Schema der Teilung der Cloake bei der Ratte nach Andersson.

richtig erkannt worden. Doch erscheint mir die Ansicht A n derssons, der die Teilung nach rein mechanischen Prinzipien erklären will, unrichtig. Er gibt ganz richtig an, dass die oralen Teile des Höckers eine grössere Wachstumstendenz haben und dasis dadurch die Gewebe des Höckers von der oralen nach der caudalen Seite verschoben werden. Es erfolgt also durch das Vorwachsen des Höckers eine Drehung der vorderen Cloakenwand, bei der die Achse dieser Bewegung am caudalen Rand der Cloakenmembran zu suchen ist, der ja durch diese Veränderung am wenigsten betroffen erscheint. Trotzdem meint Andersson, wie ich seine Ausführungen verstehe, dass die orale Cloakenwand, die im Anfang durch 
Anwachsen des Mesoderm als Darmsattel in die Cloake vorgetrieben wurde, durch die Ausbildung des Höckers gerade an diese caudalen Partien der Cloakenplatte vorgezogen werde, also an einer Stelle, an der die Verlagerung am wenigsten zum Ausdruck kommt. Der Höcker wächst ja in ventraler Richtung aus der Cloake aus. Der Darmsattel sollte aber dadurch caudalwärts gezogen werden? Die drei Schemata Anderssons legen selbst Zeugnis gegen ihn ab. Vergleicht man die Figuren a und c seines Schemas oder zeichnet man sie übereinander, indem man die hintere Cloakenwand von ihrer caudalen Grenze her zur Deckung bringt, so kann man an diesen Median-Sagittalschnitten ebenso wie z. B. an denen, die ich der Arbeit Fleischmanns entnommen habe, und an den Figuren 9 und 10 dieser Arbeit sich leicht überzeugen, dass die oral und ventral gelegenen Teile der Cloake, wo Umierengänge und Allantois münden, keineswegs in den Höcker hineingezogen wurden, ja eher noch sich in dorsaler und cranialer Richtung davon entfernt haben. Der dorsale schmale Teil der Cloake bewahrt, wie es ja auch Andersson ausdrücklich sagt, seinen Platz und entfernt sich nur mit der ganzen Anlage etwas mehr vom Rückenmark. Wenn also weder der ventrale noch der dorsale Teil der oralen Cloakenwand in den Höcker vorgezogen wird, ist es nicht recht einzusehen, warum gerade eine dazwischenliegende Wandpartie mechanisch mitgezogen werden sollte. Auch ist die Anwesenheit der mächtigen Mesodermmassen, die sich $z$ wischen Darm und Sinus urogenitalis eindrängen, durch einè einfache Umlagerung nicht zu erklären. Schliesslich muss ich neuerlich erwähnen, dass auch Anderss on die ersten und letzten Stadien des Teilungsvorganges nichi durch eine Verlagerung, sondern durch das Vorwachsen einer Scheidewand in die Cloake hinein erklären muss.

Meiner Ansicht nach geht die Teilung der Cloake folgendermassen vor sich. Das ganze um die Cloake gelegene Mesoderm 
Die Entwickelungsgeschichte des Ürogenitalsystems beim Maulwurf. 491

unterliegt einem starken Wachstumsprozess, dessen Centrum oral von der Cloake in der Gegend des Urachus zu finden ist. Das Wachstum geht von dort aus in ventrocaudaler Richtung vor sich, und zwar zeigen die mehr ventral gelegenen Teile! eine entschieden stärkere Wachstumstendenz als die dorsalen. Die ventral vom Allantoisstiel gelegenen Mesodermmassen, dio am stärksten vorwachsen, stülpen zusammen mit den lateral von der Cloakenmembran gelegenen das Ectoderm vor, so dass es zur Ausbildung des Höckers kommt. Die zwischen Allantoisstiel und Enddarm gelegene Masse wächst in derselben Richtung, gleichzeitig und im Zusammenhang mit dem übrigen Mesoderm; stülpt die orale Cloakenwand vor und bildet so den Darmsattel. Durch ein weiteres Wachstum des Mesoderms gewinnt der Anourogenitalhöcker an Länge, der Darmsattel erreicht das Ectoderm und bildet so den Damm. Dieses Vorwachsen geschieht in Form einer frontal eingestellten Falte, deren freier Rand an den Seitenwänden weiter herunterreicht als in der Medianebene. Diese halbmondförmige Form der Falte ist eigentlich selbstverständlich und stellt auch nicht einen einzig dastehen'den Fall vor. Man sieht $z$. B. bei der Unterteilung der Atrien durch das Septum primum dieses in einer ähnlichen Gestalt auftreten.

Es ist klar, dass die vorgestülpte Entodermschicht, die den Darmsattel 'bekleidet, bei seinem weiteren Vorwachsen mitwächst. Ebenso muss auch die Cloakenplatte, die man nun an Stelle der Cloakenmembran vorfindet, durch aktives Längenwachstum der weiteren Ausdehnung des Höckers folgen.

Die Art der Bildung der Cloakenplatte habe ich weiter oben kurz erwähnt. Für die Richtigkeit der Angaben A n d ers's on s, nach denen sich bereits in einem viel früheren Stadium eine' hohe Cloakenplatte durch Ausstossung der Mittelzellen der 
Cloakenmembran und Wiedervereinigung ihrer lateralen Teile bildet, finde ich an meinem Material keinen Anhaltspunkt ${ }^{1}$ ).

Die Cloakenplatte entwickelt sich nach dem früher Gesagten aus zwei Anteilen. 1. Aus der mit dem Höcker vorgestülpten Cloakenmembran, 2. aus den ventralen Anteilen der Seitenwände der Cloake, die miteinander verschmolzen sind. Die Cloakenplatte behält trotz der starken Verlängerung des Hörkers fortwährend ihre Lage bei. Sie reicht stets von seinem caudalen Rand bis zu seiner Spitze. Sie dehnt sich also durch aktives Längenwachstum aus. Ob diese Verlängerung an der Spitze der Cloakenplatte durch appositionelles Wachstum oder in der Platte selbst erfolgt, ist schwer zu entscheiden. Die Beantwortung dieser Frage ist meines Erachtens auch irrelevant, da in beiden Fällen die Struktur der Platte dieselbe sein muss, $d . h$. es muss in beiden Fällen angenommen werden, dass die äusserste Schicht der Cloakenplatte vom Ectoderm', ihre Hauptmasse aber vom Entoderm der Cloake beigestellt wird. In der Platte sind die beiden Anteile ebensowenig voneinander zu unterscheiden wie sie es in der Cloakenmembran waren.

Der Ansicht, dass die Cloakenplatte entweder im' ganzen oder wenigstens teilweise durch das Aneinanderpressen von zwei Ectodermlamellen durch das seitlich über das Niveau der Cloakenmembran hervorwachsende Mesoderm entsteht, muss ich entgegentrcien. Die „frühe Genitalrinne“, wie sie 'bei anderen Tieren beschrieben wurde, $d$. $h$. ein Tieferliegen der Cloakenmembran gegenüber dem übrigen Ectoderm, wurde als Stülze dieser Behauptung herangezogen. Beim' Maulwurf ist nichls von einer derartigen Rinne zu sehen. Die Genitalrinne, die erst in viel späteren Stadien auftritt, ist sicher nicht durch

1) Auch Henneberg kann in einer erst kürzlich er:chienenen Arbeit (Anatomische Hefte, 50. Band, Heft 3, 1914) Anderssons Befunde nicht bestätigen. 
Die Entwickelungsgeschichte des Úrogenitalsystems beim Maulwurf. 493

das Aneinanderlegen zweier Wülste, sondern durch das Auseinanderweichen zweier Ränder hervorgerufen.

Die Frage nach der Bildung des Dammes und nach der Entstehung und Bedeutung der Raphe perinei beantworte ich', wic teils aus den obigen Erwägungen, teils aus der Stadienbeschreibung hervorgeht, ganz ebenso wie Andersson. Der Damm ist nichts anderes als der Darmsattel, der die Cloakenplatte durchwächst und das Ectoderm erreicht. Die Raphe perinei ist ein Rudiment der Cloakenplatte.

Die Resorption des Schwanzdarmes geht auch beim Maulwurf in craniocaudaler Richtung vor sich. Seine innige Beziehung zu den Blutgefässen des Schwanzes, die Anderss on beschrieben hat, konnte auch ich erkennen. Ob aber die Resorption durch eine Einwirkung der embryonalen Blutkörperchen bewirkt wird, wage ich nicht $z u$ entscheiden.

\section{Die weitere Entwickelung des Urogenital- höckers.}

Eine zusammenfassende Beschreibung der weiteren Entwickelung kann in Kürze gegeben werden. Nach der Unterteilung der Cloake in Sinus urogenitalis und Enddarm ist auch der Anourogenitalhöcker in zwei Teile getrennt. Der orale Teil ist der Urogenitalhöeker. Ans ihm entwickelt sich der Phallus. Der caudale Teil bildet die Analregion. Beide Teile enthalten tinen Abschnitt der Cloakenplatte.

Der Urogenitalhöcker ist bei Beginn dieser Entwickelungsperiode (VII. Stadium) ein hoher schmaler Zapfen, der in oraler Richtung aus der Bauchwand vorragt. Seine Basis wird von zwei niederen Wülsten flankiert, die an seiner oralen Seite ineinander übergehen. An seiner caudalen Seite trägt or eine longitudinale Rinne, die an seiner Basis am tiefsten, gegen seine Spitze hin allmählich verstreicht. Über ihren Zusammenhang 
mit der Cloakenplatte wurde bei der Beschreibungl der Stadien das Nötige gesagt.

Der Urogenitalhöcker des' Maulwurfs entwickelt sich bei beiden Geschlechtern in derselben Weise. Nur bleibt er bei Weibchen stark im Wachstum zurück.

Die weitere Veränderung des Höckers beruht hauptsächlich auf der Ausbildung der Präputialfalten. Es scheint dies eine Fortsetzung desselben Wachstumsprozesses zu sein, der die Verlagerung der Cloakenmembran an die caudale Seite des Höckers, die Entstehung des Höckers und die Teilung der Cloake verursachte.

Es ist nämlich wieder ein von einem oral vom Sinus gelegenen Centrum ausgehender Wachstumprozess, der den Höcker allmählich in caudaler Richtung umbiegt und ihn mit dem mächtigen Mantel umgibt, den die Präputialfalte darstellt. Diese beiden Veränderungen vollziehen sich gleichzeitig und im' Zusammenhang miteinander.

Man sieht den Höcker im VIII. Stadium rechtwinklig von der Bauchwand abstehen, während sich die beschriebenen kleinen Wülste zu dem starken Ringwulst vereinigt haben, der an ider oralen Seite des Höckers seine grösste Ausdehnung erreicht.

Beim IX. Stadium ist die Caudalkrümmung des Höckers vollzogen. Die Präputialfalte bekleidet ihn bis über seine Krümmung hinaus.

Bei der Ausbildung dieser Falte spielen sich folgende Vorgänge ab.

Die anfänglich beschriebenen Wülste beginnen zu wachsen. Sie vereinigen sich zuerst an der oralen Seite der Höckerbasis und gehen hier ohne sichtbare Grenze ineinander über. Es entsteht so ein halbmondförmiger Wulst, der den Höcker umgreift. Seine beiden Enden stchmiegen sich enge dem Höcker an und gehen distal in die der Cloakenplatte angelagerten Meso- 
dermlippen übier. Sie 'sind anfänglich noch durch die 'entstehende Urogenitalrinne voneinander getrennt. Uber diese hinweg legen sie sich aber, beim weiteren Anwachsen, aneinander und verwachsen, aber nicht ohne dass die Verwachsung äusserlich durch eine seichte Furche, innerlich durch das Bestehenbleiben einer dünnen, epithelialen Raphe gekennzeichnet bleibt. Es ist also aus dem halbmondförmigen ein Ringwulst geworden (IX. Stadium). In diesem Stadium erscheint er als eine basale Anschwellung des Höckers. Er ist zwar, bis auf die unmittelbare Nachbarschaft der Cloakenplatte, überall durch eine scharfe Furche sowohl von dem freigebliebenen Teil des Höckers wie auch von der Bauchwand getrennt. Doch folgt das Ectoderm diesen Furchen, ohne dass irgendwo von einer Einstülpung des Ectoderms etwas $\mathrm{zu}$ sehen wäre.

Der Ringwulst wächst nun weiter gegen die Höckerspitze vor. Dabei drängt er sich aber nicht wie bisher gleichsam zwischen das Mesoderm und das Ectoderm des Höckers ein, sondern er erhebt sich in einer Falte, die den Höcker enge umgreift. Dabei vereinigt sich die innere Epithelbekleidung dieser Falte, die das spätere Präputium darstellt und daher Präputialfalte genannt wurde, innig mit dem Integument des Höckers, auf diese Weise eine dünne Ectodermlamelle darstellend, die in das Höckermesoderm hineinzuragen scheint, aber nur die Grenze zwischen diesem und dem Gewebe der Präputialfalte bezeichnet. Wir kennen freilich kein Stadium, bei dem diese innere Epithelbekleidung der Falte getrennt von dem Höckerectoderm zu sehen wäre. To u rn e u x beschreibt den Vorgang sehr anschaulich als ein Emporgleiten des Präputiums über die Glans.

Infolge der Entstehungsart der Lamelle, die als Glandarlamelle beschrieben wurde, liegt ihr Ursprungsrand in einer Linie, die das distale Ende der Präputialfalte bezeichnet. Ihr freier Rand ist die basale Umschlagstelle dieser Falte. 
Beim weiteren Wachstum der Präputialfalte wird auch die Glandarlamelle immer länger. Ihr freier Rand bleibt an derselben Stelle, nur ihr distaler Beginn wird eben immer weiter gegen die Höckerspitze hin verschoben, bis die Präputialfalte die Spitze erreicht hat.

Die Bildung des Präputiums geht also beim Maulwurf in derselben Weise vor sich, wie sie schon Tourneux (C. R. Soc. Biol. 1887) und vor ihm Schweigger-Seidll und andere beschrieben haben.

Retterer hat eine andere Erklärung für die Entstehung des Präputiums gegeben und seine Theorie wurdé neuerlich von $\mathrm{F}$ le is chmann und seiner Schule wieder aufgenommen. Nach der Ansicht dieser Autoren ist es nicht eine Falte; welche über die Oberfläche der Glans weggleitend hinaufwächst und so das Präputium und die Glandarlamelle bildet, sondern es ist diese Lamelle eine, ectodermale Einbuchtung, welche von dem distalen Höckerende aus in diesen hineinwächst und so den ursprünglich einfachen Höcker in Glans beziehungsweise Clitoris und Glandarium oder Clitorium; zwei Synonyma für Präputium, unterteilt.

Die 'Durchsicht einiger Transversal- und Sagittalschnitte durch den Urogenitalhöcker in diesem Stadium lassen alle Anzeichen eines selbständigen Wachstums der Glandarlamelle vermissen, hingegen sind genug Merk'male im Mesoderm der Präputialfalte; die anzeigen, dasis der Sitz des Wachstumprozesses dorthin zu verlegen ist. An der Reihe der Modelle ist; wie bei der Beschreibung hervorgehoben wurde, das Wachstüm der Präputialfalte deutlich zu konstatieren.

A'usserdem können die Resorptionsvorgänge, durch die Fle is chman das Verschwinden der freien Spitze des Urogenitalhöckers im Präputialsack erklären muss, in keiner Weise nachgewiesen werden. 
Die Entwickelungsgeschichte des Trogenitalsystems beim Maulwurf. 497

Auch 'A ndersson, der diese Verhältnisse bei den Nagetieren studiert hat, schliesst sich der Ansicht Tourneux' an. Dort ist eine ausführliche Widerlegung der Ansichten Fleischmanns zu finden.

Ein 'weiterer Beweis' dafür, dass die Präputialfalte in der beschriebenen Art verwächst, ist in ihrem innigen Verhältnis zur Bildung des Urogenitalrohres aus der Urogenitalrinne zu finden.

Ich habe am Anfange dieses Kapitels wieder die Rinne erwähnt, die von der Basis des Höckers gegen seine Spitze verstreicht.

Ich will an dieser Stelle nur kurz darauf verweisen, dass Fleischmann and seine Schule das Vorhandensein einer Urogenitalrinne leugnen, obwohl alle anderen Autoren, die sich mit der Entwickelungsgeschichte des Urogenitalsystems beschäftigen, sie beschrieben haben. Eine ausführliche Erläuterung dieser Frage findet sich bei Andersson in Kapitel III der dritten Abteilung. Es bedarf keines anderen Beweises für das Vorhandensein einer Rinne als der Anblick der Modellfigur 8 des Stadium VIII oder der in Figur 13 dargestellten Schnitte $\mathrm{h}$ und i des Stadium IX, des Schnittes $\mathrm{c}$ in Stadium X, die von jedem unbefangenen Beobachter eben alst Rinne, beziehungsweise als Querschnitte durch eine Rinne gedeutet werden müssen. $\mathrm{Ob}$ man nun diese Rinne Urogenitalrinne oder wie Fleischmann Orificium urogenitale nennen will, ist Geschmackssache. Von einer schweren Täuschung $R$ athkes und aller anderen Forscher zu reden, erscheint jedenfalls unberechtigt.

Die Betrachtung der Serien zeigt, dass sich die Rinne durch ein Auseinanderweichen der beiden Mesodermlippen, die die Cloakenplatte umschliessen, bildet. Damit ist auch eine teilweise Trennung der Cloakenplatte in zwei Lamellen verbunden. Gelegentlich der Beschreibung der Serien wurde auf 
degenerierte Epithelzellen zwischen beiden Schichten verwiesen, die auch Andersion als Kittzellen beschrieben hat. Mit Berufung auf diese Kittzellen erklärt Andersson die Entstehung der Urogenitalrinne einfach durch das Auseinanderweichen der zwei Schichten, durch deren Zusammengepresstwerden die Cloakenplatte entstanden ist. Auch wenn diese beiden Schichten nicht vorgebildet sind, muss ein derartiger centraler Zellzerfall eintreten, wenn eine solide Zellmasse in zwei Teilen auseinandergezogen wird. Ich glaube den Grund dieses Auseinanderweichens angeben zu können.

Wie oben erwähnt, hat T o u r n e u x schon das Ubergehen der caudalen Ränder der Präputialfalte in die Lippen der Urogenitalrinne beschrieben. Dasselbe beschreibt Andersson, und auch meine Befunde stimmen hiermit überein. Es ist meines Erachtens unzweifelhaft, dass die kräftige Wachstumstendenz, die der Präputialfalte innewohnt, sich in einer Zug. wirkung auf die mit ihr verbundenen Teile, die mit ihrem Wachst tum nicht gleichen Schritt halten können, äussern muss. Als Folge dieser Zugwirkung sehe ich das Auseinanderweichen der die Cloakenplatte umschliessenden Ränder und damit die Bildung der Rinne an. Als Bekräftigung dieser Ansicht führe ich an, dass die Urogenitalrinne gleichzeitig mit der Bildung der Präputialfalte beginnt und dass ihre Vertiefung mit dem Vorwärtswachsen der Falte einhergeht, so dass immer der ticfste Punkt der Rinne gerade am distalen Ende der Präputialfalte gelegen ist, wo eine Zugwirkung am meisten zur Geltung kommen kann, ja dass sich an dieser Stelle sogar ein rautenförmiges Grübchen bildet, dessen proximale Begrenzung durch die Präputialfalte, die distale durch die Lippen der Urogenital. rinne beigestellt wird. Schliesslich dass die Rinne gegen die Höckerspitze $\mathrm{zu}$, wo eine derartige Zugwirkung noch nicht vorhanden ist, verstreicht. 
Die Entwickelungsgeschichte des Urogenitalsystems beim Maulwurf. 499

Um nun wieder zu der Weiterentwickelung der Präputialfalte zurückzukehren, so zeigt sich, dass diese, indem sich ihre Enden an der Caudalseite des Höckers vereinigen, dabei die Urogenitalrinne überdeckt und sie in ein Rohr verwandelt, dessen Wände von der Rinne und dem epithelialen Belag der Präputialfalte gebildet wird. Die Glandarlamelle tritt ebenfalls mit dem Rohr in Verbindung. Auf diese Weise wird durch das Verwachsen der Präputialfalte die ganze Urogenitalrinne allmählich in ein Rohr verwandelt, ein Vorgang, der eben ohne ein aktives Vorwachsen der Präputialfalte sich auf keine Weise erklären lässt.

Das so entstandene Urogenitalrohr wird aber noch, während sich dieser ganze Prozess abspielt, verlagert. Und zwar weichen als Fortsetzung der beschriebenen Vorgänge die beiden Lippen der früheren Genitalrinne noch weiter auseinander, so dass das Urogenitalrohr tiefer in die Cloakenplatte hineinrückt. Über dem Rohr schliessen sich die beiden Mesodermlippen wieder eng aneinander. Das Rohr liegt dann ganz eingebettet im Mesoderm des Phallus und steht mit der Glandarlamelle nur mehr durch einen ganz dünnen Epithelstreifen, der zwischen den beiden Lippen bestehen bleibt, in Verbindung.

Der beschriebene Prozess spielt sich beim Maulwurf bei beiden Geschlechtern in gleicher Weise ab. Nur ist beim Weihchen, wie oben erwähnt, der Geschlechtshöcker viel kleiner geblieben. Das Präputium wächst beim weiblichen Tier weit über die Glans hinaus.

Schon bei Beginn dieser Entwickelungsperiode differenziert sich im Mesoderm des Höckers das spätere Phallusgerüst.

\section{Die weitere Entwickelung der Analregion.}

Wenn der herunterwachsende Darmsattel das Ectoderm erreicht und den Damm gebildet hat, liegt zwischen dem Uro. 
genitalhöcker und dem Schwanz, der sich durch eine deutliche Furche absetzt, eine flache, wenig modellierte Region. Sie ist lateral durch zwei Höckerchen begrenzt, so dass sie etwas eingesunken erscheint. In ihrer Mitte ist am Modell die Darmöffnung durch ein seichtes Grübchen gekennzeichnet. Die Serie zeigt, dass dieses Grübchen durch den caudalen Teil der Cloakenplatte gebildet wird, der jetzt als Analplatte die Darm: öfnung 'verschliesst. Zwischen ihr und der Cloakenplatte verläuft eine Epithelverdickung über den Damm, die Raphe perinei. Sie ist ein Rest der Cloakenplatte. Der in diesem. Stadium noch stark ventral gekrümmte Schwanz liegt der Analregion und der Caudalseite des Höckers an (Stadium VI).

Bei späteren Stadien wird gleichzeitig mit der Streckung desı 'Schwanzes die Region noch einfacher. Die beiden lateralen Wülste sind verschwunden. Die Analplatte wird dünner, ihre Zellen degenerieren. Doch verschliesst sie lden Darm noch immer und 'bildet eine leichte Einsenkung' in der Mitte der ganz flachen Analgegend (Stadium IX).

Beim 'X. Stadium liegt die Analöffnung als' ein transversaler Spalt an der Spitze einesi niederen Kegelstumpfes, der bis zur Beendigung der Entwickelung wächst und beim erwachsenen Tier die beschriebene kegelförmige Papille bildet, die an Grösse beinahe dem Präputium gleichkommt.

Bei älteren Embryonen sieht man das Darmlumen am Grund idieses Kegelstumpfes von Zelldetritus verlegt, den Resten der Analplatte. Bis zu dieser Stelle reicht typisches Darmepithel, distal davon ist dieser neu entstandene Darmteil von verhornendem, ectodermalem Pflasterepithel ausgekleidet.

Es wulstet sich also das rings um die primäre Analöffnung gelegene Ectoderm vor und bildet,dso nach innen eine ectodermale Pars analis recti, nach' aussen die Papilla analis..

Für den Beweis, dass dieser Darmteil wirklich so entsteht, ist das Verhalten der Analdrüse wichtig. 
Die Entwickelungsgeschichte des Urogenitalsystems beim Maulwurf. 501

Ihre erste Anlage wurde als drei Epithelsprossen beschrieben, welche von der Raphe perinei etwa in der Mitte ihres Verlaufes ausgehen. Wenn nun die Ausführungsgänge der Analdrüse beim erwachsenen Tier auf der obersten Kante der Analpapille zu finden sind, kann man sich dies wohl nicht anders erklären, als dass der zwischen Analplatte und Mündung der Analdrüse gelegene Teil des Ectoderms in die Pars analis recti einbezogen wurde, womit ja auch die oben wiederholten histologischen Befunde übereinstimmen.

Es entwickelt sich also bei Talpa ausser der primären Analöffnung, die durch die Analplatte verschlossen bleibt und wie diese aus Ecto- und Entoderm besteht, eine ectodermale Verlängerung 'des Darmrohres, die mit einer rein ectodermalen, sekundären Analöffnung an der Oberfläche mündet.

Ahnlich wie das hier geschehen ist, beschreibt $\mathrm{Ke}$ ibel (1896) die Entwickelung der äusseren Afteröffnung. Uml die primäre äussere Darmöffnung entstehen Ausbuchtungen der Gewebe, sio dass die ursprüngliche Offnung zuerst auf dem: Grund einer Grube liegt, die sich sodann zu einem ectodermalen Darmrohr zusammenschliesst.

Retterer kommt zu demselbien Resultat wie Keibel, wenn er auch die Bildung der ectodermalen Parsl analis recti in Verfolgung seiner Verwachsungstheorie zu erklären sucht.

Fleischmann vertritt die Ansicht, dass die primäre Analöffnung zum funktionierenden Anus' wird und dieser eine entodermale Bildung ist. Mit der Entstehung dieser primären Analöffnung beschäftigt sich besonders $\mathrm{Sch}$ warztrauber. Andersson verwirft zwar die Erklärungen Schwarztrau ber s über die Entstehung des Anus. Er ist der Meinung, dass sich die Analöffnung im Bereiche der früheren Cloakenplatte bildet, also ebenso wie ich den Vorgang auch hier beschrieben habe. Doch vertritt auch er die Ansicht, dass die 
primäre Analöffnung persistiert, und versucht das auf Grund seiner Untersuchungen $\mathrm{zu}$ beweisen.

Er unterscheidet zwei verschiedene Bildungsarten. Es bildet sich nämlich bei Formen, bei denen der Anus durch einen kurzen Postanalteil von der Schwanzwurzel getrennt ist, die Analöffnung auf dem Grunde der Caudoperinealfurche, die den Schwanz von dem Körper abtrennt. Diese Falte verflacht allmählich durch die Streckung des Schwanzes und die Abflachung der Dammgegend. Dadurch kommt die Analöffnung an die Oberfläche.

Bei anderen Formen ist der „Postanalteil" länger. Bei diesen "scheint die Analöffnung bald auf der Bauchseite ein Stück vor dem Schwanz, bisweilen mit angeschwellten Rändem hervorzutreten"

Andersson führt selbst als die einzigen Gründe, die gegen seine Auffassung sprechen, an, erstens „die Vergrösserung der Pars analis recti, die unbestreitbar stattgefunden hat", und das histologische Verhalten der Geweie. Den letzteren Grund erledigt er nur flüchtig. Er meint, dass das Wachstum dieses Darmteils auf dem Eigenwachstum der Analplatte beruht, die ja als Teil der Cloakenplatte ebenso aus Entoderm wie aus Ectoderm aufgebaut ist, und dass diese also Gewebe liefern könne, die, obwohl entodermalen Ursprungs, doch ectodermalen Charakter annehmen können. Es mag dies richtig sein, doch ist bei einer Bildung, die distal von der Analplatte gelegen ist, die ectodermalen Charakter zeigt und ohne detutliche Grenze in das umgebende Ectoderm übergeht, ihre ectodermale Ab'stammung jedenfalls wahrscheinlich', ztumal da auch die äusserste Schicht der Analplatte aus Ectoderm besteht.

Auf Seite 216 schreibt Andersson: „Sollte eine derartige ectodermale Umwachsung (wie sie Keibel beschreibt) stattfinden, so müsste sie sich als eine von der übrigen Analregion abgesetzte röhrenförmige Erhebung um die Analöffnung 
herum zeigen ..." Genau das isl, wie beschrieben, bei Tatpa der Fall.

Andersson meint, dass das Eigenwahshum der Analplatle genügt, un das Längerwerden der Pars inalis recti $\% 1$

erklären. Solange man einen Ectodermzuschuss nicht deullich nachweisen kann, ist die Annahme eines solchen rollkommen unberechtigt. Die Analöfnung persistient während des ganzen Lebens und kein ectodermaler Zuschuss zu derselben findet statt, sondern es ist der distale feil des Darmes hauptsächlich entodermalen Ursplungs, obgleich die Analmündung selbst, da sie auf Grundlage der Cloakenplalte entslanden isi, aus Ectoderm aufgebaut ist, das nur bisweilen um sie herum angeschwelle Ränder bildet.

Der geforderte Nachweis scheint mir mit Hilfe der Analdrüsen und der verhällnismässig lang persistierenden Clonkenplatte geliefert.

Ich stehe daher nicht an zu erklären, dass die persistierende Analöffnung eine sekundäre, aus Ectoderm gebildete ist und dass ebenso die Pars analis recti eine rein ectodermale Bildung darstellt.

Es sind schliesslich noch die Analhöcker zu erwähnen, die seit $R$ e i chel wiederholt beschrieben wurden. Bei lalpa sind sie in meinem Stadium VI gut ausgebildet. Sie verschwinden aber im Verlaufe der weiteren Entwickelung spurlos. Es sind zufällige Bildungen, die mit der Bildung der Analöffnung gewiss nichts zu tun haben.

\section{Die weitere Entwickelung des Sinus urogenitalis. Die inneren Harn- und Geschlechtsorgane.}

Auch die Entwickelung des Sinus urogenitalis spielt sich bei beiden Geschlechtern von Talpa europaea in derselben Art $a b$. 
Der Sinus urogenitalis entsteht aus idem. ventralen Teil der Cloake durch das: Einwachsen des Mesodermsattels. Dieser Teil der Claake ist ursprünglich ein sagittal eingestellter Spaltraum. An seiner oralen Wand mündet der Allantoisgang. Nahe davon ist an der lateralen Wand die Mündung des Urnierenganges zu finden. Die ventrale Wand ist die Cloakenmembran. Dieser Raum geht zuerst ohne Grenze in die dorsalen Cloakenpartien über, unterscheidet sich aber, wie beschrieben, durch ein höheres Epithel. Gleichzeitig mit dem Einschneiden des Mesodermsattels weiten sich die Mündungen der Urnierengänge trichterförmig aus und bilden die Cloakenhörner. Dieser Teil des Sinus ist dann der breiteste. Er hat, wie beschrieben, einen halbmondförmigen Querschnitt. Gegen seine caudale Wand, die nach der Ausbildung des Anourogenitalhöckers und der damit verbundenen Verlagerung der Cloake durch die Cloakenplatte gebildet wird, verengert sich der Sinus zu einem Rohr, das vor vollendeter Teilung noch mit dem Enddarm in Verbindung ist.

Ist diese Teilung einmal vollzogen, so hat der Sinus urogenitalis bei beiden Geschlechtern.die Form erreicht, wiel sie bei Beschreibung des VII. Stadiums ausführlich dargelegt wurle. Die Cloakenhörner sind vollständig in die Wand des Sinus einbezogen worden. Ureter und Wolffsche Gänge rücken mit ihren Mündungen auseinander, bis diese an der dorsalen Fläche des Sinus und etwas ciadal von den lateral einmündenden Ureteren ihren endgültigen Platz erhalten.

Zwischen den Mündungen der Wolff schen Gänge entsteht eine leichte Furche als Grenze zwischen Sinus urogenitalis und der Blasienanlage. Auch diese ist durch eine Furche unterteilt.

Ihre caudale Partie, die durch die Ureterenostien ausgezeichnet ist, liegt noch in der Verlaufsrichtung des Sinus uro- 
Die Entwickelungsgeschichte des Urogenitalsystems beim Maulwurf. 505

genitalis. Sie ist offenbar hauptsächlich! aus den Cloakenhörnern entstanden.

Der craniale Teil sitzt fast rechtwinkligt deml caudalen auf. Er ist mit diesem erst durch eine weite Offnung in Verbindung, die sich im Verlaufe der weiteren Entwickelung zu einem transversalen Spalt verändert.

Bei der Bildung dieses Teiles werden wohl auch Anteile des Allantoisganges in die Blaseneinlage einbezogen.

Das Mesoderm, das sich jetzt zu differenzieren beginnt, bildet um den cranialen Blasenteil, dạs Corpus vesicae, ein reichliches Muskellager. Ein anderer kräftiger Muskel bildet sich um den Sinus urogenitalis, während der caudale Blasenteil, die Pars trigonalis vesicae, in Bindegewebe eingebettet ist.

Bis hierher ist kaum ein Unterschied zwischen der Entwickelung beim Männchen und beim Weibchen zu machen.

Von nun an aber bleiben beim Weibchen während des Wachstums, das ja noch unzweifelhaft fortdauert, die Proportionen der einzelnen Gebilde ziemlich gleich, so dass wir beim Weibchen eine kurze, wenig geschwungene Harnröhre haben, zu der sich der Sinus urogenitalis infolge Verkümmerung der Wolff schen Gänge entwickelt.

Die Müllerschen Gänge, die, ohne in den Sinus zu münden, an seiner dorsalen Wand herunterwachsen, erreichen das Ectoderm erst im extrauterinen Leben, wie gelegentlich der Beschreibung des erwachsenen Tieres erwähnt wurde. $\mathrm{Ob}^{\prime}$ vielleicht Reste der Cloakenplatte an der Bildung der Vagina Anteil haben, konnte nicht festgestellt werden. Jedenfalls ist die Stelle, an der die Müllerschen Gänge das Ectoderm erreichen, schon frühzeitig durch eine Epithelanhäufung gekennzeichnet.

Der männliche Sinus urogenitalis wird im Verlauf der weiteren Entwickelung viel länger und schlanker. Besonders auffallend wird der Geschlechtsunterschied auch durch das 
verschiedene Verhallen der accessorischen Geschlechtsdrüsen, deren Entwickelung schon hei ler Beschreibung der Stadien genug berücksichtigt wurde. Die sehr schwach entwickelten M üll er schen Gänge enden blind in einer durch die Mündung der Urnierengänge in den Sinus urogenitalis vorgehobenen Falte.

Damit scheinen die Verhältnisse, wie sie beim erwachsenen Tier beschrieben wurden, erreicht. 


\section{Literaturverzeichnis.}

L. G. Andersson, Untersuchungen uber die Entstehung der Husseren Genitalorgane und des Afters bei den Nagetieren. Arkiv för Zoologi. Bd, 5.

Dr. J. Böhm, Die äusseren Genitalien des Schafes. Gegenbauers morph. Jahrb. Bd. 34.

L. Bolk, Zur Entwicklung und vergl. Anatomie des Tractus urethrovaginalis der Primaten. Zeitschr. Morph. Anthrop. Stuttgart. Bd. 10.

R. Bonnet, Uber die Entwicklung der Allantois und die Bildung des Afters bei den Wiederkanuern etc. Anat. Anzeiger. Bd. 3.

G. Born, Die Entwicklung der Ableitungswege des Urogenitalapparates und des Dammes bei den Saugetieren. Ergebn. Anat. und Entwicklgs. Gesch. Bd. 3.

A. I. P. v. d. Broek, Zur Entwicklungsgeschichte des Urogenitalkanales bei Beutlern. Anat. Anzeiger, Bd. 32.

- Entwicklung und Bau des Urogenitalapparates der Bentler und dessen Verhältnisse zu diesen Organen anderer Stuger. Morph. Jahrbuch. Bd. 41.

Buhler, Entwicklungsgeschichte der Kopulationsorgane der Amnioten in Hertwigs Handbuch der Entwicklungalehre.

H. Dimpfl, Die Teilung der Kloake bei Cavia cobaya. Morph, Jahrb. Bd.. 35.

J. Disse, Utber die Entwicklung des Kloakenhöckers bei Talpa europsea Sitzungsber. Gesellsch. Naturw Marburg 1904.

- Untersuchungen über die Umbildung der Kloake und Entstehung des Kloakenhöckers bei Talpa europaea. Anat. Hefte. Bd. 27.

W. Dürbeck, Die äusseren Genitalien des Schweines, Morph. Jahrb. Bd. 36. Die Husseren Genitalien der. Hauskatze. Morph. Jahrb. Bd. 36.

A. Flei вchmann, Morphologische Studien über Kloake and Phallus der Amnioten, IV. Teil. Dio Säugetiere. Morph. Jahrb. Bd. 30.

- V. Teil die Stilistik d. Urodurums und Phallus bei den Amnioten. Morph. Jahrb. Bd. 30.

- VII. Teil Historisch- kritische Betrachtungen. Morph. Jahrb. Bd. 32.

- VIII. Teil Stilistik des Urodäums. Morph. Jahrb. Bd. 32.

- Die Stilcharaktere am Urodäum u. Phallus. Morph. Jahr. Bd. 36. 
Literatarverzeichnis.

A. Fleischmann, Das allgemeine Resultat meiner Phallusstudien. Sitzungsbericht phys. med, Soz. Erlangen. Bd. 38.

R. Gerhardt, Morphol, und biol. Studien uber die Kopulationsorgane der Sulugetiere. Jenaische Zeitschr. Naturw. Bd. 39.

- Der gegenwartige Stand der Kenntnisse von den Kopulationsorganen der Wirbeltiere insbesondere der Amnioten. Ergeb. u. Fortschr. Zoologie Bd. I.

S. Gross, Beitrage zur Anat. der akzess. Geschlechtsdrasen der Insektivoren und Nager. Arch. Mikr. Anat. Bd 66.

C. Grubar, Bau und Entwicklung der ausseren Genitalien bei Cavia cobaya. Morph. Jahrb. Bd. 36.

B. Henneberg, Beitrag zur Entwicklung der ausseren Genitalorgane beim Sauger, I Teil. Anat. Hefte. Bd. 50.

W. K a udern, Beiträge zur Konntnis der minnlichen Geschlechtsorgane der Insektivoren. Z. Jahrbuch. Abt. Morph. Bd. 24.

- Stadien uber die mannlichen Geschlechtorgane von Insektivoren und Lemuriden. Z. Jahrbuch Abt. Morph. Bd. 31.

I. Kazzander, Zur Anatomie d. Penis beim Manlwurf. Z. Anz. Bd. 39.

Fr. Keibel, Die Entwicklungsvorgänge am hintern Ende des Meerschweinchenembryos. Arch. f. Anat. u. Phys. 1888.

- Zur Entwicklungsgeschichte des menschlichen Urogenitalapparates. Arch. f. Anat. u. Phys. 1896.

G. v. Mihalcovics, Untersuchungen ther die Entwicklung des Harns und Geschlechtsapparates der Amnioten. Internat. Monatsschr. f. Anat. u. Hist. Bd. 2.

W. Nagel, Über die Entwicklung der Sexualdräsen and der äusseren Geschlechtsteile beim Menschen. Sitzungsber. K. Preuss. Akad. 1888.

- Uber die Entwicklung des Urogenitalsystems beim Menschen. Archiv f. mikr. Anat. Bd. 34 .

- Uber die Entwicklung der Urethra und des Dammes beim Menschen. Archiv f. mikr. Anat. Bd 40.

Th. Oudemans, Die akzessorischen Geschlechtsdrüsen der Săgetiere. Haarlem 1892.

H. Rathke, Abhandlungen zur Bildungsweise and Entwicklungsgeschichte des Menschen und der Tiere. 1832.

M. Rauther, Uber den Genitalapparat einiger Nager u. Insektivoren, insb. die akzessorischen Genitaldrüsen derselben. Jenaische Zeitschr. Naturw. Bd. 38.

P. Reichel, Die Entwicklung des Dammes und ihre Bedeutung für die Entstehung gewisser Missbildungen. Zeitschr. f. Geburtsh. u. Gynak. Bd. 14.

- Die Entwicklnng der Harnblase und Harnröhre. Verh. d. phys. med. Ges. Würzburg. Bd. 27.

E. Retterer, Note sur le développement du penis et du squelette du gland chez certains rongeurs. C. $R$ Soc. Biol. 1887.

- Sur l'orgine et l'évolution de la région anogénitale des mammifères. Journ. de l'anat. et phys. 1890. 
Literaturverzeichnis. Für alle Figuren gültige Bezeichnungen. . 509

E. Retterer, Du développement du prépuce, de la couronne du gland et du col du penis chez l'embryon bumain. C. R. Soc. Biol. 1890.

- Des glandes annexées à l'appareil ano-génitourinaire du cobaye femelle et de leur développement. C. K. Soc. Biol. 1903.

- Sur le développement du penis et du clitoris chez le foetus humain. Journ. d. l'anat. et phys. 1892.

I. Schwarztrauber, Kloake und Phallus des Schafes u. Schweines. Morph. Jahr. Bd. 32.

- Das Analrolrr des Schafes. Morph. Jahrb. Bd. 35.

H. Strahl, Zur Bildung der Kloake des Kaninchenembryos. Archiv f. Anat. u. Phys. 1886.

F. Tourneux, Sur le développement de la verge et spécialement du gland, du prépuce, et de la portion balanique du canal de l'urèthre chez l'homme. C. R. Soc. Biol. 1887.

- Sur le premier développement du clonque, du tubercule gènital et de l'anus chez l'embryon de mouton. Journ. de l'anat. et phys Bd. 24.

- Sur le développemont et l'évolution du tubercule génital chez le foetus humain dans les deux sexes. Journ. de l'anat, et phys. Bd. 25.

Torsten Pehrson, Beiträge zur Kenntnis der ausseren weiblichen Genitalien bei Affen, Halbaffen und Insektivoren. Anat. Anzeiger. Bd. 46.

Für alle Figuren gültige Bezeichnungen:

$$
\begin{aligned}
& \mathrm{AD}=\text { Analdrise } \\
& \mathrm{AG}=\text { Allantoisgang } \\
& \mathrm{AH}=\text { Analhücker } \\
& \mathrm{AP}=\text { Analplatte } \\
& \text { AUH }=\text { Anourogenitalhöcker } \\
& \mathrm{B}=\text { Blass } \\
& \mathrm{CD}=\text { Cowpersche Drüse } \\
& \mathrm{CF}=\text { Corpus fibrosum } \\
& \mathrm{CL}=\text { Clitoris } \\
& \mathrm{CS} \text { = Cremastersack } \\
& \mathrm{CV}=\text { Corpus vesicae } \\
& \mathrm{ChD}=\text { Chorda dorsalis } \\
& \mathrm{D}=\text { Darm } \\
& \mathrm{DD}=\text { Ductus deferens } \\
& \mathrm{E}=\text { Ektoderm } \\
& \mathrm{ED}=\text { Enddarm } \\
& \mathrm{GL}=\text { Glandarlamelle } \\
& \mathbf{K}=\text { Kloake }
\end{aligned}
$$

$$
\begin{aligned}
& \text { KP }=\text { Kloakenplatte } \\
& \text { KM }=\text { Kloakenmembran } \\
& \text { MG }=\text { Müllerscher Gang } \\
& \text { NA }=\text { Nierenanlage } \\
& \text { NR }=\text { Neuralrohr } \\
& \text { P }=\text { Prostata } \\
& \text { Pr. = Praepntium } \\
& \text { PT }=\text { Pars trigonalis vesica } \\
& \text { R }=\text { Rektum } \\
& \text { RW }=\text { Ringwulst } \\
& \text { SD }=\text { Schwanzdarm } \\
& \text { SU }=\text { Sinus urogenitalis } \\
& \text { U }=\text { Urethra } \\
& \text { UH }=\text { Urogenitalhöcker } \\
& \text { UR }=\text { Urogenitalrinne } \\
& \text { Ur }=\text { Ureter } \\
& \text { V }=\text { Vagina } \\
& \text { WG }=\text { Wolffscher Gang }
\end{aligned}
$$


Anatomische Hefte. I. Abt. 166. Heft (55, Bd., H. 2).

Tafel 37.

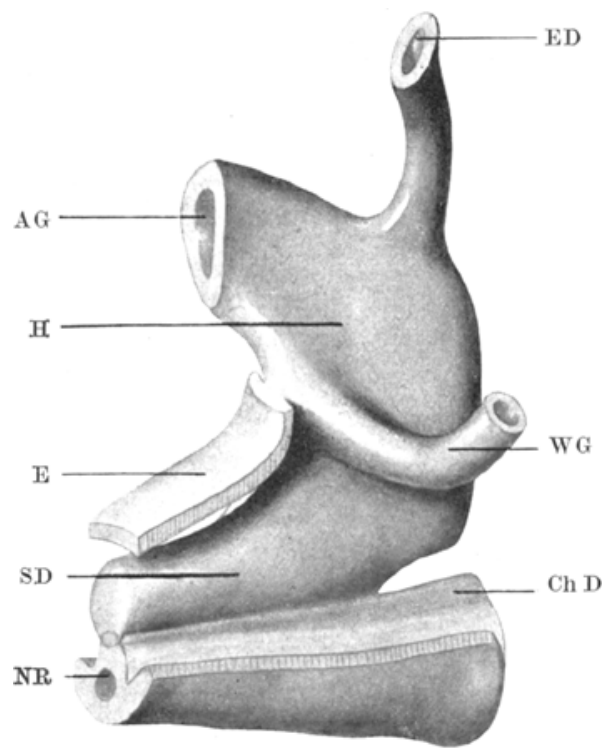

Fig. 1.

Modell der Kloake eines Embryo von $35 \mathrm{~mm}$ gr. L. von links gesehen. Neuralrohr und Chorda dorsalis, sowie das Ektoderm in der Umgebung der Kloakenmembran wurden mitmodelliert. Modellvergrösserung $1 \times 200$. 1/2 cler Modellgrösse.

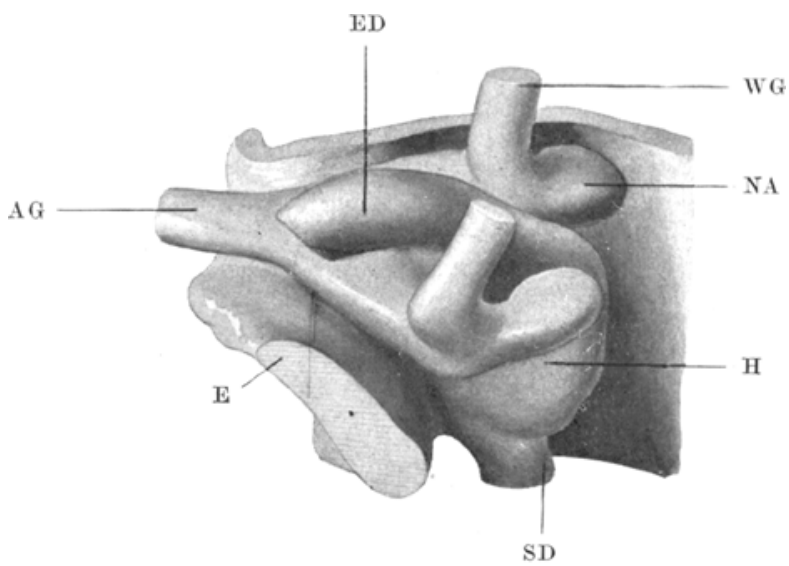

Fig. 2.

Modell der Kloake eines Embryo von $5 \mathrm{~mm}$ gr. L. von links und oben gesehen. Das Ektoderm der linken Körperhälfte abgetragen. Modellvergrơssserung $1 \times 200$. ${ }^{1 / 2}$ der Modellgrồsse. 


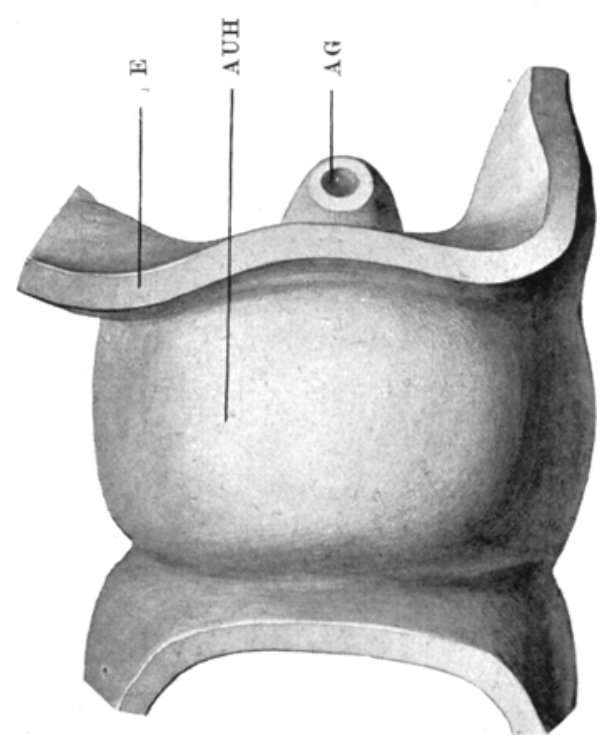

Fig. 3.

Modell des Anourogenitalhöckers eines Embryo von $6 \mathrm{~mm}$ gr. L, von vorne. Die Schnittflăchen des Ektoderms der Nabelhornie und des Schwanzes dem Beschaner zugekehrt. Modellvergrösserung $1 \times 200$. 1/2 der Modellgrösse.

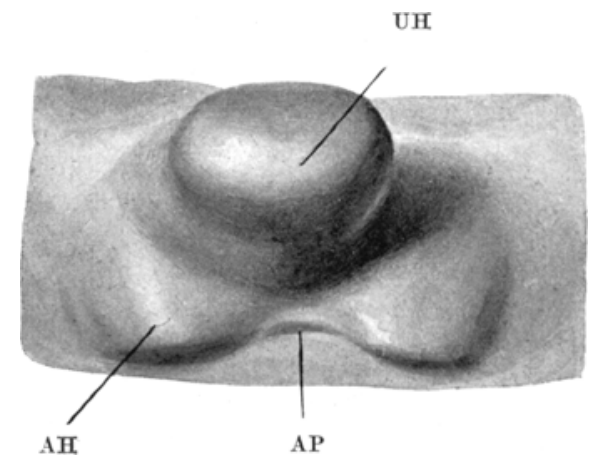

Fïg. 4.

Modell des Urogenitalböckers und der Analregion eines Embryo von $11 \mathrm{~mm}$ Scheitel-Steisslänge von vorne gesehen. Modellvergrösserung $1 \times 100$. $1 / 2$ der Modellgrösse. 


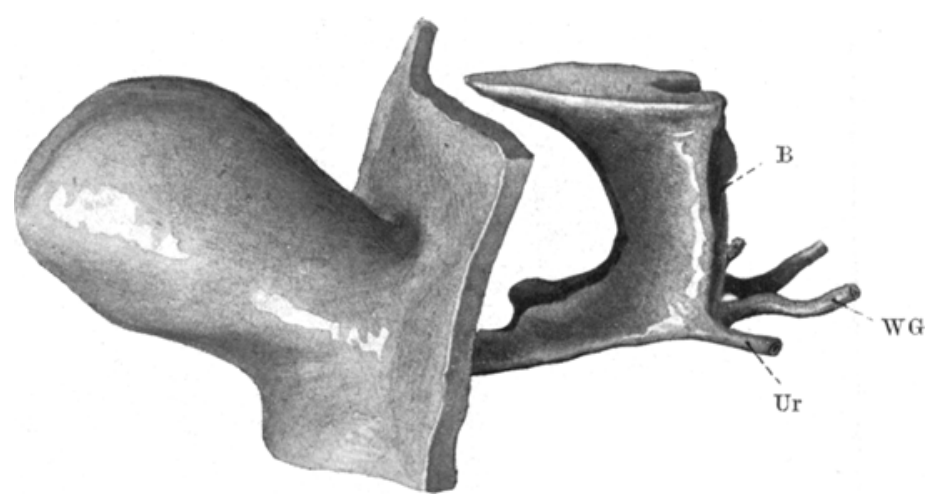

Fig. 5.

Modell des Urogenitalhöckers und des Sinus urogenitalis eines Embryo von $12 \mathrm{~mm}$ Scheitel-Steisslänge von links gesehen. Modellvergrösserung $1 \times 100$; 1/2 der Modellgrösse.

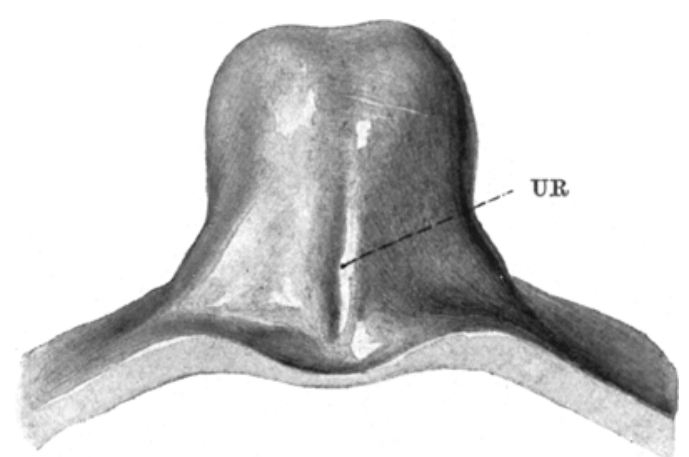

Fig. 6.

Modell des Urogenitalhöckers eines Embryo von $12 \mathrm{~mm}$ Scheitel-Steisslänge. Kaudalansicht. Modellvergrösserung $1 \times 100$. 1/2 der Modellgrösse. 


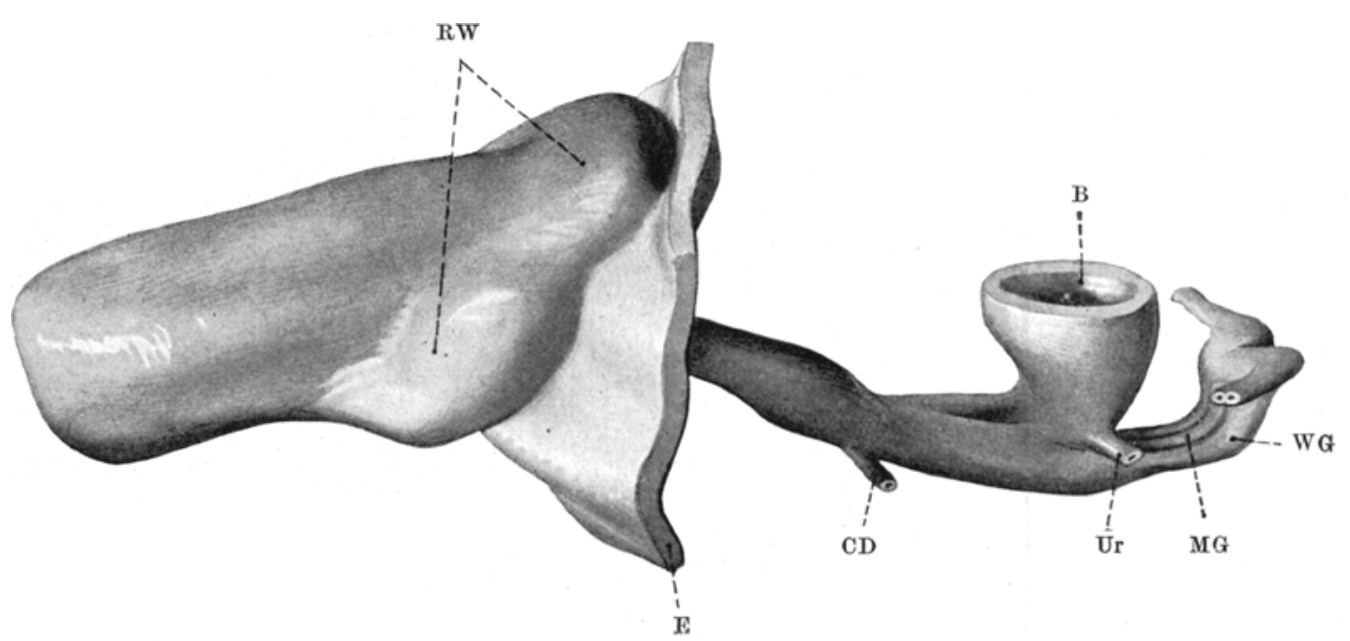

Fig. 7.

Modell des Urogenitalsystems eines Embryo von $17,5 \mathrm{~mm}$ gr. L. von links gesehen. Modellvergrösserung $1 \times 100$. 1/a der Modellgrösse.

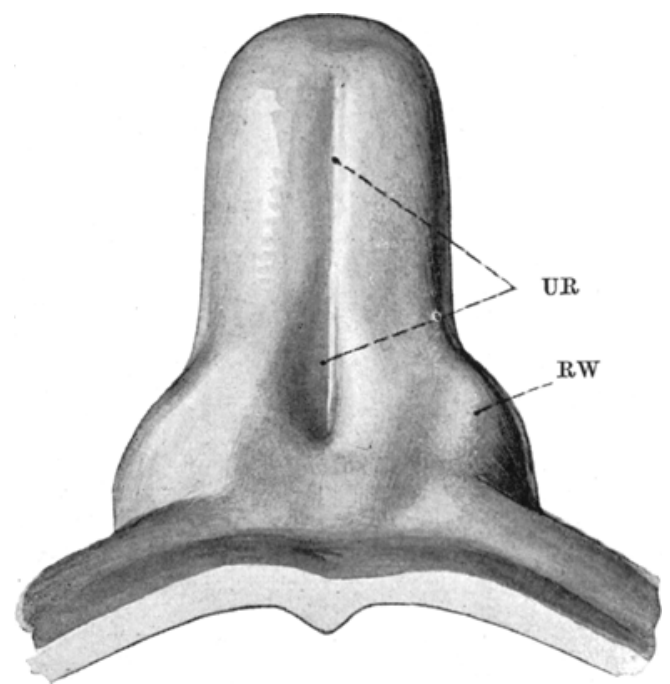

Fig. 8.

Modell des Urogenitalhöckers eines Embryo von $17,5 \mathrm{~mm}$ gr. L. von kaudal gesehen. Modellvergrösserung $1 \times 100$. 1/2 der Modellgrösse. 


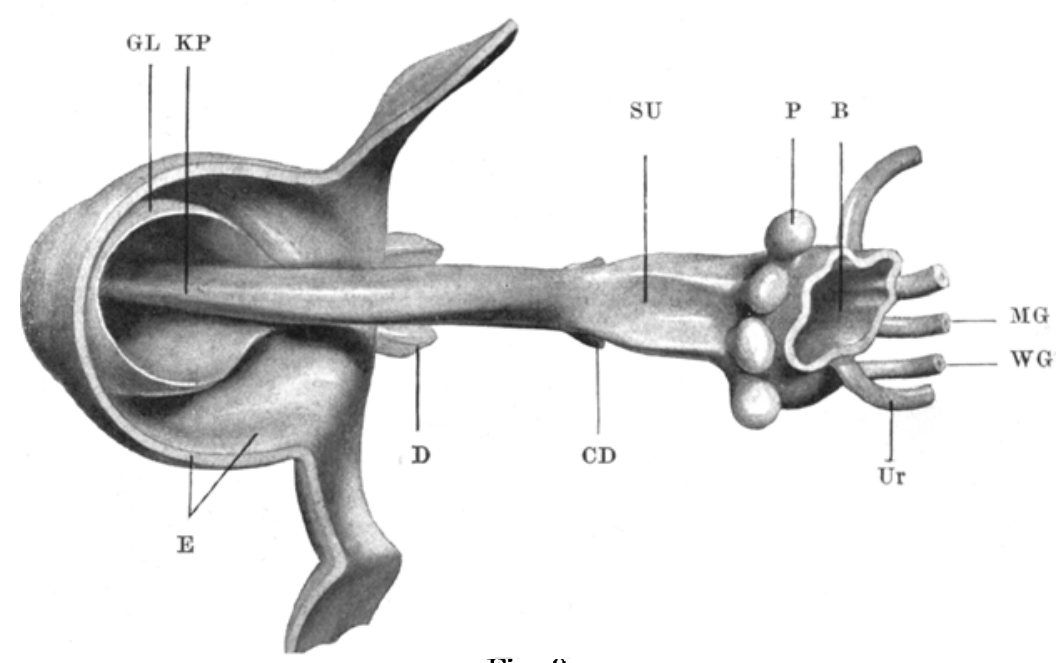

Fig. 9.

Modell des Urogenitalsystems eines Einbryo von $23 \mathrm{~mm}$ gr. L. von kranial gesehen. Der kraniale Teil des Urogenitallöckers wurde abgetragen. Modellvergrösserung $1 \times 100$. 1/2 der Modellgrösse.

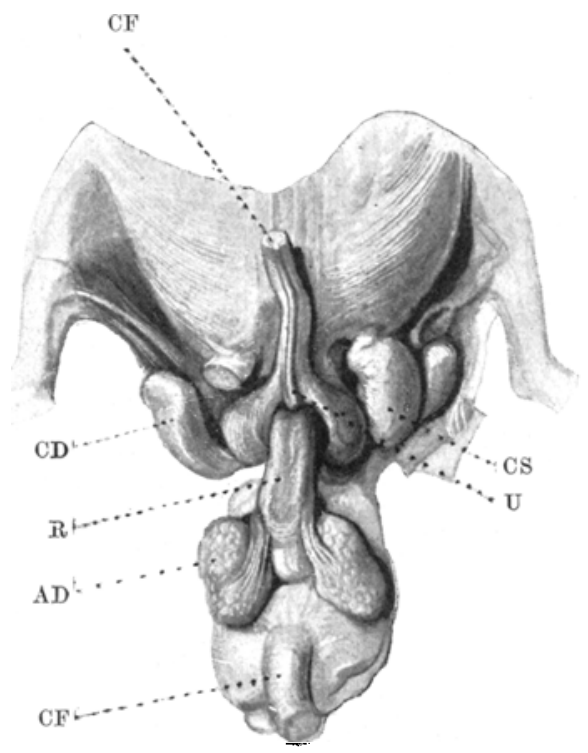

Fig. 10.

Genitale eines erwachsenen männlichen Maulwurfs: - Đì Haut ist abprăpariert, das Corpus fibrosum durchschnitten und mit dem Prapirtium zurückgeschlagen. Der mediale Lappen der Analdrüse wurdèentférnt. Nátürliche Grösse. 